\title{
Movimientos residencia-trabajo y estructura metropolitana. Cambios en el área metropolitana de Bilbao: 1980-2001
}

\author{
JOSEBA JUARISTI LINACERO \\ Departamento de Geografía, Prehistoria y Arqueología \\ Universidad del País Vasco \\ joseba.juaristi@ehu.es
}

Recibido: 18 de Diciembre de 2009

Enviado a evaluar: 10 de Enero de 2010

Aceptado: 24 de Febrero de 2011

\section{RESUMEN}

En este artículo se estudia la evolución de la estructura jerárquica del área metropolitana de Bilbao en el periodo comprendido entre los años 1980 y 2001, a través del análisis de los movimientos residencia/trabajo.

Las transformaciones socioeconómicas de este periodo pueden resumirse bajo el epígrafe de "transición postfordista": cambios demográficos, económicos, y de las pautas de movilidad, en las que algunos autores han querido ver el paso desde estructuras espaciales monocéntricas hacia estructuras policéntricas en las metrópolis.

Para el estudio de los movimientos residencia/trabajo se han empleado varias técnicas: análisis de la estructura nodal, parámetros de fricción de la distancia e índices de entropía.

Se concluye que, a pesar del gran aumento de la movilidad, tanto interna como externa al área metropolitana, durante este intervalo temporal, no se produce la emergencia de un esquema policéntrico, sino que se refuerza un esquema de cuatro subcentros que se vislumbraba a comienzos de los años 1980. Los cuatro subcentros articulan áreas de diferentes características en cuanto a las funciones económicas y residenciales. Además, la primacía de Bilbao se intensifica en cuanto a la atracción de empleo externo.

Palabras clave: Estructura metropolitana. Policentrismo. Estructura nodal. Fricción de la distancia. Entropía.

\section{Commuting and metropolitan structure. Changes in Bilbao Metropolitan Area 1980-2001}

\begin{abstract}
The evolution of urban hierarchical structure of the metropolitan area of Bilbao is analysed during the period 1980-2001, using commuting data.

The socioeconomic transformations of this period could be denoted under the brand of "postfordist transition" in which dramatic changes take place in demographic and economic structures, along with commu-


ting patterns in metropolitan areas. Some authors suggest that, after this transition, a new polycentric structure or centres emerged in substitution of previous monocentric structure.

In order to analyse the commuting data, a set of techniques is used here: nodal structure of links between places, distance decay parameters, and entropy indexes.

Despite of the great increase of commuting during this period, both inside and outside of the metropolitan area, one conclusion of this article is that no polycentric structure takes place. The structure of four sub-centres organizing a second level of sub-areas is identified using the techniques mentioned above, sub-centres that were emerging in the early 1980'. The four sub-areas have different economic and residential functions. In addition, the primacy of Bilbao intensifies in terms of attracting outside employment.

Keywords: Metropolitan structure. Polycentrism. Nodal Structure. Distance decay parameters. Entropy.

\section{Déplacements maison/travail et la structure métropolitaine. Changements dans la zone métropolitaine de Bilbao. 1980-2001}

\section{RÉSUMÉ}

Dans cet article nous étudions l'évolution de la structure hiérarchique de l'aire métropolitaine de Bilbao dans la période allant de 1980 à 2001, à partir de l'analyse des mouvements domicile/travail.

Les transformations socio-économiques de cette période pourraient être qualifiées de « transition postfordiste » : changements démographiques, économiques, ainsi que modèles de mobilité, où certains auteurs ont voulu déceler la transition des structures spatiales monocentriques vers des structures polycentriques dans les métropoles.Pour l'étude des mouvements domicile/travail, nous avons employé plusieurs techniques : analyse de la structure nodale, paramètres de friction de la distance et indices d'entropie.

De tout cela nous concluons que, malgré l'importante croissance de la mobilité, interne comme externe à l'aire métropolitaine, pendant cet intervalle temporel, aucune émergence du schéma polycentrique n'a lieu, à moins que ne se renforce le schéma de quatre sous-centres déjà perçue au début des années 1980. Les quatre sous-centres articulent des aires de caractéristiques différenciées, selon leurs respectives fonctions économiques et résidentielles. Par ailleurs, la primauté de Bilbao s'intensifie pour attirer emploi à l'extérieur.

Mots-clé : Structure métropolitaine. Polycentrisme. Structure nodale. Friction de la distance. Entropie.

\section{INTRODUCCIÓN}

El objeto de este artículo consiste en analizar los cambios en la estructura metropolitana a través del estudio de los esquemas de los movimientos residencia-trabajo en un periodo de 20 años. Por estructura metropolitana entendemos aquí las relaciones jerárquicas que se producen entre el centro (cuya existencia se considera indispensable para la existencia de una metrópolis, ya que etimológicamente metrópolis equivale a "ciudad- madre"), y los diferentes subcentros. En este caso las relaciones 
corresponden a las formas de vinculación de los lugares de residencia y empleo, vistas a través de un esquema espacial de veintiséis municipios.

El interés de este trabajo estriba, por una parte, en los cambios económicos y demográficos que se producen en el periodo analizado. Así, el área metropolitana de Bilbao ${ }^{1}$ es un ejemplo de lo que algunos autores han llamado llaman "transición postfordista".

Por otra parte, desde el punto de vista teórico, en este trabajo utilizamos conceptos y técnicas que cuentan con una cierta tradición en el estudio de la jerarquización de centros y subcentros urbanos, como el de estructura nodal, así como en las teorías de interacción espacial (fricción de la distancia y entropía). Estas cuestiones metodológicas nos parecen importantes puesto que suponen un acercamiento (o reacercamiento) a aspectos teóricos que quedan soslayados - si no obviados - en muchos estudios sobre los movimientos residencia/trabajo en ámbitos metropolitanos.

En cuanto al primer aspecto, la transición postfordista describe un desplazamiento desde una estructura económica basada en industrias fabriles, con abundancia de grandes empresas y unidades productivas que se benefician de economías de escala interna, hacia otra estructura en la que predominan los servicios, aunque también las fábricas en unidades productivas más pequeñas, con una mayor flexibilidad de operaciones (mano de obra, subcontratación, mercados, etc). En geografía urbana la idea de postfordismo fue analizada por David Harvey (1989), y las consecuencias espaciales sobre las metrópolis han sido destacadas por autores de corrientes postmodernas, en especial por Edward Soja (2000). En la geografía urbana española también se ha incorporado esta terminología (Artigues et al., 2006).

Veamos algunas características de esta transición en el área que nos ocupa. Entre el año 1981 y el año 2001, el área estudiada pasa de 936.848 habitantes a 865.799.

Sin embargo, el empleo sigue una dinámica contraria a la de la población total, debido al envejecimiento de la población - con un aumento en la franja de las edades adultas así como del empleo femenino, con el consiguiente aumento de la tasa de empleo. Así, en 1981 la cifra del empleo total en el A.M. de Bilbao era de 266.239 personas, mientras que en 2001 era de 335.214 personas. En este intervalo, la composición de la base económica también se transforma, ya que en 1981 la mano de obra en manufactura supone el $42,7 \%$, con cerca de 114.000 empleos, mientras que en el año 2001 la cifra absoluta se ha reducido casi a la mitad, y supone el $19,2 \%$ del empleo total.

Por otra parte, en el intervalo analizado hay cambios demográficos destacables, como la disminución del tamaño medio de las familias, cambios económicos, como el aumento de los ingresos medios familiares que conllevan nuevos hábitos de consumo y ocio, así como la generalización del uso del automóvil. Una consecuencia de ello es el aumento de la movilidad, tanto hacia los lugares de trabajo como a nuevos espacios de consumo, con una política de infraestructuras de transporte que en esta área se traduce, fundamentalmente, en los accesos al municipio de Bilbao por auto-

1 En los sucesivo la nombraremos como, A.M. de Bilbao, o A.M.B. 
móvil, así como a algunas infraestructuras que rompen la tradicional división del A.M. de Bilbao en dos zonas separadas por la ría: la Margen Izquierda y la Margen Derecha: en el año 1983 se inaugura el puente de Rontegi, favoreciendo la movilidad entre esas dos zonas. En el transporte colectivo el hito dentro de este periodo ha sido la puesta en marcha del Metro, en 1995. Otros factores de la movilidad son consecuencia del establecimiento de infraestructuras de servicios metropolitanas localizadas en municipios externos al de la ciudad central, o el crecimiento de los ya existentes, tales como instalaciones universitarias y colegios, centros sanitarios, y la proliferación de grandes superficies comerciales en la periferia. Por otra parte hay que considerar que el mercado de la vivienda también se expande, en un sentido espacial, hacia áreas más alejadas del centro de las metrópolis, creando relaciones de dependencia residencia/trabajo más variadas (centro/periferia; periferia/periferia; centro metropolitano/centro metropolitano, u otras combinaciones).

En relación con los cambios económicos, se han producido transformaciones importantes de los usos del suelo como consecuencia de la desindustrialización, pasando una buena parte de las superficies dedicadas a industrias fabriles a convertirse en áreas residenciales, así como a otros usos: transporte, almacenaje, superficies comerciales, cuyas consecuencias sobre la movilidad aún no se han estudiado con detalle.

Este artículo intenta aportar evidencias empíricas al debate sobre el surgimiento de estructuras metropolitanas policéntricas, y que suele asociarse con una cierta "explosión" de la movilidad propia de la etapa postfordista. Así, Peter Hall señalaba la tensión entre dos modelos de ciudad: un modelo centrípeto, favorecido por las infraestructuras de transporte colectivo, que favorecen el acceso al centro de la ciudad, frente a un modelo policéntrico, basado en el uso del automóvil privado, que favorece la suburbanización (Hall, 2000).

El concepto de policentrismo, tal como se utiliza en geografía y economía urbana tiene un doble origen. Comienza a aplicarse a los estudios sobre la ciudad a finales de los años 1960, a veces con otros sinónimos tales como multicentrismo, centros múltiples, multinuclearidad, etc. como un enfoque para superar los modelos y teorías que conciben la ciudad como un ente monocéntrico, tales como las de Burgess de estructura interna de la ciudad centrada en el CBD, la de Alonso de las rentas del suelo urbano, o las de las densidades urbanas de Colin Clark, proponiéndose modelos y teorías alternativas, como es bien conocido en la literatura geográfica. Hay que señalar, en este sentido, que las teorías de lugares centrales, como teorías que tratan de múltiples centros jerarquizados, no ocuparon un lugar destacado en este debate, quizá porque se consideraban más bien teorías sobre los sistemas de ciudades, aunque muy tempranamente se había postulado su aplicación a escala intraurbana (Isard, 1956).

El policentrismo como concepto político tiene su origen en la idea de "unidad en la diversidad" 2 y llega a entenderse como un modelo óptimo de gestión que evita las

2 El término fue aplicado por primera vez por Palmiro Togliatti a la situación de los diversos partidos comunistas nacionales tras el fin de la era estalinista en la Unión Soviética, en 1956. 
polarizaciones y las disimetrías en el reparto del poder. Pero esta teoría, a su vez, está relacionada con las teorías del "orden espontáneo", es decir del surgimiento de organización a partir de situaciones iniciales caóticas o simplemente aleatorias.

Estas formas de orden espontáneo también han sido investigadas desde una perspectiva teórica, aplicadas a la geografía urbana, como los modelos de auto-organización de Allen y Sanglier (1979), que intentan mostrar bajo qué condiciones puede producirse la emergencia de esquemas jerárquicos partiendo de situaciones no-jerárquicas. El concepto de auto-organización proporciona nuevas perspectivas para entender los procesos de transformación de los sistemas urbanos. Más recientemente se continúan aplicando estas ideas con otros modelos similares (Roca Cladera y Marmolejo, 2006).

Por este doble origen, el policentrismo se ha convertido tanto en un objeto de estudio empírico como en una meta de desarrollo urbano y regional. En el primer aspecto, no existe hasta el momento un acuerdo para definir un sistema urbano como policéntrico sobre bases estadísticas o funcionales, a pesar de algunos intentos recientes de sistematización (Hall y Pain, 2007), ni tampoco se ha definido la escala geográfica sobre la cual se debe aplicar esta idea, aunque la mayor parte de los estudios hacen referencia a grandes metrópolis europeas, americanas, o asiáticas de varios millones de habitantes. En el segundo aspecto tampoco están claros los beneficios que pueden esperarse de la organización urbana policéntrica. Así, se ha llegado a hablar de la moda del "policentrismo" (Davoudi, 2004) como objetivo a alcanzar en la política territorial en diferentes escalas.

Pero la "moda" no tiene en cuenta las posibles desventajas de la organización urbana policéntrica; en este sentido, algunos estudios recientes subrayan que el policentrismo se construye a costa de una mayor separación de los lugares de residencia y trabajo (Aguilera, 2005), y que puede estar relacionado con la disimetría entre la rigidez del mercado de la vivienda y la flexibilidad de la localización de la mano de obra en el contexto metropolitano.

Cuando las ideas sobre policentrismo llegan a la geografía urbana por el camino de las interpretaciones postmodernas que consideran la ciudad o los sistemas de ciudades como un tablero de juego del capitalismo (Dear y Flusty, 1998), llegan a abandonarse importantes conceptos sobre la estructura, jerarquía y organización espacial que subyacen a las transformaciones de las ciudades (Clark, 2000). Si uno atiende a la terminología empleada en numerosos artículos que estudian estas transformaciones, puede llegar a la conclusión de que las jerarquías urbanas se han volatilizado. Se estudian más "áreas" y "redes" que estructuras o jerarquías. No se tiene en cuenta la realimentación de los sistemas jerárquicos de centros partiendo de las condiciones previas a las "nuevas realidades", expresión muy frecuente en aquellos trabajos que se dirigen más a mostrar los resultados de la movilidad que a analizar las causas.

El enfoque sobre las estructuras de la movilidad en áreas urbanas tiene sus antecedentes remotos en los estudios sobre las relaciones entre estructura y proceso (Griffith y Jones, 1980), que establecieron un cierto dualismo en los trabajos de investigación sobre la ciudad según dos tipos de enfoques: así los estudios de la localización física de actividades económicas y residencia, reflejados en mapas de usos del suelo, se suponía que tenían que ver más con los aspectos estructurales de la orga- 
nización urbana, mientras que los estudios sobre flujos y movimientos tenían que ver más con los procesos, con el "comportamiento" del sistema, basándose en la dualidad (being, behaving). Posteriormente esta dualidad se superó teniendo en cuenta la consideración de que la durabilidad, o la permanencia de ciertas relaciones funcionales jerárquicas, eran en sí mismas una evidencia de relaciones estructurales, necesitando además incorporar la perspectiva de la evolución del sistema (becoming).

El concepto de estructura espacial es relevante para el análisis de la realidad urbana, como ha señalado Escolano: "Entendemos la estructura espacial no como un datum, sino como un modo de organización espacial verificable, que se puede caracterizar por atributos cualitativos o parámetros como la densidad, la conectividad, niveles de jerarquía, porosidad,... en todo caso, el de estructura espacial es un concepto fundamental para la construcción de una imagen racional de la ciudad" (Escolano, 2006, 105).

En este artículo, la escala del estudio es una escala intra-metropolitana, que permite evaluar con detalle los cambios en los esquemas de subcentros. Existe un estudio a escala de sistema urbano regional, pero con una mayor limitación temporal, y referida a municipios por encima de los 10.000 habitantes (Juaristi Linacero, 2003).

Este artículo se organiza en seis apartados. En el primero de ellos tratamos de las fuentes estadísticas y la metodología aplicada, lo que nos permite, hasta cierto punto, el obtener información sobre la estructura metropolitana partiendo de fuentes diversas. En el segundo analizamos los cambios en la movilidad en el contexto de la Comunidad Autónoma del País Vasco, ya que consideramos aquí al área metropolitana como un sistema limitado pero abierto. En el tercer apartado identificamos el sistema de subcentros partiendo de los datos de 1980, y las transformaciones que se observan en la estructura jerárquica hasta el año 2001. En el cuarto apartado analizamos las características de los subcentros en cuanto a sus atributos de origen (residencial) y destino (laboral), así como de las transformaciones que son consecuencia de la reestructuración postfordista sobre los usos del suelo. En el quinto apartado valoramos cómo ha afectado la movilidad a la fricción de la distancia, y sus diferentes valores según el papel de los municipios del área en los mercados locales de trabajo. En el sexto apartado utilizamos los índices de entropía para analizar el sistema metropolitano a través del tiempo, la evolución de las desigualdades existentes entre la distribución estadística de los orígenes y de los destinos, así como a las características de diversidad de orígenes y destinos de cada municipio, lo cual nos permite profundizar en el concepto de "centro". Finalmente, en un último apartado resumimos las conclusiones obtenidas.

\section{FUENTES Y METODOLOGÍA}

La fuente principal de este trabajo han sido los censos y padrones en los que se recoge la información a escala municipal sobre los lugares de trabajo y de residencia, en este caso, los correspondientes a los años 1986, 1991, 1996 y 2001, que se elaboraron para el conjunto de la Comunidad Autónoma Vasca ${ }^{3}$. No obstante, estas fuentes presentan

3 En lo sucesivo, C.A.V. 
algunas diferencias y debilidades. Así, el padrón de 1986 no tiene en cuenta los movimientos con origen en Bilbao. Eustat (Servicio Vasco de Estadística) ha comunicado que no elaborará los datos del padrón de 2006, lo que induce a considerar que, con propósitos comparativos, son más fiables las estadísticas de los años censales (1991 y 2001), que las de los años padronales (1986 y 1996). De todas formas, en el presente trabajo, los análisis estadísticos y cuantitativos se han aplicado a todas las fechas consideradas. Por otra parte, se han utilizado otras fuentes, como la Encuesta de Movimientos origen/destino elaborada en 1980 dentro de un estudio sobre la problemática del transporte comarcal en Bilbao (Ayuntamiento de Bilbao, 1980), que maneja una división municipal similar a las anteriores, e incluso desagrega el municipio de Bilbao en cuatro zonas. También se ha tenido en cuenta un trabajo referido a mitad de los años 1980 (Díez Nicolás y Alvira Martín, 1985), aunque su desagregación espacial es menor que la considerada aquí, y por ello su validez es muy limitada para nuestro propósito.

En estos análisis se ha tenido en cuenta la diferente naturaleza de los datos. Así la Encuesta de 1980 se basa en datos obtenidos a partir de muestras estadísticas de movimientos que luego se generalizan al total de la población existente, mientras que los datos censales comprenden solo la población ocupada. La encuesta citada incluye movimientos de ida y vuelta, y por ello el resultado es una matriz casi simétrica respecto a la diagonal, es decir, un mismo encuestado cuenta en dos celdillas distintas de la matriz, que son simétricas, mientras que las tablas de datos origen/destino censales son matrices dirigidas, y por ello nos permiten conocer o discernir ciertas características estructurales de los orígenes y los destinos, asociadas, respectivamente, a los lugares de residencia y de trabajo.

Las técnicas de análisis que empleamos aquí permiten conciliar unas fuentes estadísticas de naturaleza diversa: como sabemos, no existen recuentos censales sobre movimientos residencia/trabajo establecidos de forma sistemática para la CAV hasta el padrón de 1986, pero los conceptos empleados aquí permiten, usando las tablas de la Encuesta de 1980, extender el análisis del proceso a un periodo de 20 años. Para el conjunto del Estado español, sólo existe una fuente estadística estandarizada y homologable desde el año 2001, y que ha sido explotada recientemente por Feria (2008), ofreciendo una visión estática de la delimitación de áreas metropolitanas. Hay que señalar que el enfoque de este artículo no va dirigido a delimitar un área de influencia de los centros urbanos en su extensión actual, sino a indagar en la naturaleza de las relaciones jerárquicas. En geografía urbana hay un abundante trabajo empírico dedicado a ello, como se recoge en un artículo de Feria (2004), en particular, el referente a la delimitación de áreas urbanas y mercados locales de trabajo basados en umbrales de tamaño urbano y cifras (absolutas y relativas) de interacción. Los métodos de las áreas de cohesión desarrollados por Castañer (2001), u otros posteriores, si bien tienen la utilidad de mostrar las fases de la expansión metropolitana, no indagan en la naturaleza del soporte territorial de la jerarquía de centros, aunque su máximo valor puede estribar en la comparación de distintos sistemas regionales metropolitanos de acuerdo con umbrales de interacción consensuados por especialistas.

Tampoco se han realizado estudios comparativos a escala del estado español entre las "nuevas realidades urbanas" que desvelan los movimientos residencia/trabajo y las delimitadas con criterios anteriores, por ejemplo, los utilizados por 
Esteban (1981) para las áreas metropolitanas españolas; o con los resultados obtenidos con la utilización del concepto de potencial de población por Calvo Palacios y Pueyo Campos (1992), de un gran impacto visual cartográfico. Es más, sería necesario considerar si el concepto de potencial de población, más "democrático" que los movimientos de los trabajadores, en el sentido de que incluye a toda la población, no sería más útil para conocer la extensión del fenómeno metropolitano aplicando parámetros de fricción obtenidos con estudios empíricos adecuados.

Las delimitaciones de áreas metropolitanas soslayan el problema de los movimientos pendulares diarios entre distintas metrópolis, y los mapas obtenidos no tienen nada que ver con la experiencia vital diaria de los trabajadores, que es sustancialmente "bipolar" (trabajo/hogar), e incluso con experiencias de frecuencia semanal de movimientos de trabajadores a escalas mayores.

La supuesta utilidad estadística que se esgrime como motivo para la realización de estudios de delimitación funcional de áreas metropolitanas también queda en entredicho, ya que la estadística debe servir para la comparación temporal, y por tanto, para la mayoría de los propósitos, la identidad del área de estudio debe mantenerse a través del tiempo.

Finalmente, en el contexto de la aplicación de las delimitaciones con propósitos administrativos se está produciendo una desmotivación para tales estudios, en parte por la peculiar situación del estado español, ya que las autonomías tienen competencias para realizar sus propias delimitaciones metropolitanas, y desde el punto de vista de la ciencia de la administración, por el ensayo de formas flexibles de organización de las realidades metropolitanas, más adaptables a los cambios funcionales que la creación de de áreas administrativas específicas (Navarro Gómez, 2008).

Para nuestro propósito, hemos considerado aquí una delimitación espacial del A.M.B. coincidente con la comarca estadística Gran Bilbao, integrada por 26 municipios, y utilizada en las estadísticas oficiales del Gobierno Vasco (Eustat). Hay otras delimitaciones espaciales tales como el área funcional del Bilbao Metropolitano ${ }^{4} \mathrm{o}$ la presentación de la metrópoli de Bilbao como integrada por 30 municipios $^{5}$. La elección de este marco espacial se debe, en primer lugar a las necesidades de com-

4 Esta es el área considerada en las Directrices de Ordenación del Territorio del País Vasco (DOT) (Gobierno Vasco, 1994). El área está integrada por 35 municipios. En dichas Directrices no hay una justificación metodológica de la subdivisión del territorio de la CAV en "áreas funcionales", que, de hecho, se convierten en "áreas plan" con unos límites definidos. Esta área es mucho menor de la delimitada por Esteban (51 municipios para 1985), utilizando criterios estándar internacionales. (Esteban, 1981).

5 Es el marco espacial inicialmente utilizado por la asociación Bilbao Metrópoli 30, encargada de gestionar el Plan Estratégico del Bilbao Metropolitano. Si bien esa denominación respondió en su día (en 1991, año de la fundación de esa asociación) a la búsqueda de un nombre eufónico. En Diciembre de 2009 los documentos del Plan Estratégico indicaban que el área está integrada por 44 municipios. En el momento de la revisión de este trabajo (19-10-10), se afirma: "La Asociación "Bilbao Metropoli-30" se ha constituido para realizar proyectos de planificación, estudio y promoción, dirigidos hacia la recuperación y revitalización del Bilbao Metropolitano, definido como una realidad social y económica sin unos límites geográficos precisos y cuya existencia se ha proyectado por todo su entorno regional e internacional" (el subrayado es nuestro). http://www.bm30.es/Welcome_es.html. Más recientemente, Feria (2008) ha estimado que el área metropolitana de Bilbao la integran 93 municipios. 
paración, debido a la existencia de fuentes estadísticas, en particular la Encuesta del año 1980. Con ello abarcamos una secuencia temporal de veinte años, un "plazo medio" en el que se pueden analizar transformaciones. Por otro lado, los subcentros metropolitanos identificados se sitúan dentro de esta área. Hay que subrayar que cualquier otra delimitación hubiera planteado problemas similares. Sin embargo, debemos enfatizar que delimitación no significa estudiar un sistema cerrado, sino que, desde la perspectiva del estudio de los sistemas, es lo que se puede llamar "nivel de interés" de un sistema abierto: la estructura jerárquica cambia porque cambia la movilidad hacia el exterior y desde el exterior, y cambian las medidas numéricas mediante las cuales analizamos el cambio estructural.

La metodología para desvelar las características de la estructura metropolitana tiene ya cierta tradición en los estudios de interacción espacial, y en nuestro caso, se dirige a tres finalidades concretas:

-En primer lugar, a conocer la estructura nodal de los subcentros del área metropolitana de Bilbao, para identificar los subcentros y valorar los cambios cualitativos en estas estructuras a lo largo de un periodo de veinte años.

-En segundo lugar, a aplicar algunas medidas, como el parámetro de fricción de la distancia para valorar la magnitud de los cambios a escala metropolitana. La disminución de este parámetro, a escala del área analizada, muestra la tendencia general del sistema, pero también, aplicada a los movimientos con origen en cada municipio, muestra diferencias espaciales que caracterizan mercados locales de trabajo, así como su transformación.

-En tercer lugar, a conocer las características generales estructurales del A.M. de Bilbao a través de índices de entropía que permiten valorar la intensidad o el grado de generalización de los movimientos. Este tipo de índices nos permite ponderar el diferente papel que juega la localización concreta de los orígenes, por un lado, y de los destinos, por otro, en la configuración del sistema, así como su tendencia evolutiva. Ya que, lo largo del periodo estudiado, las concentraciones espaciales de residentes y empleos varían, estos cambios dibujan tendencias estructurales que se pueden evaluar.

\section{CAMBIOS EN LA MOVILIDAD A ESCALA REGIONAL}

Examinamos ahora la movilidad en una escala superior al "nivel de interés", es decir, a escala de la comunidad autónoma del País Vasco.

Las tablas que presentamos a continuación recogen las cifras de movimientos residencia/trabajo en tres escalas distintas. La primera tabla presenta las relaciones de los movimientos con origen en Bilbao (municipio central del área metropolitana que cuenta con la tercera parte de la población metropolitana), y con destino en el espacio del "resto" de los municipios del A.M., y asimismo, con el "resto" de la Comunidad Autónoma.

La lectura de la tabla 1 nos revela un aumento generalizado, en términos absolutos, de la movilidad en los tres ámbitos considerados. Pero si convertimos esas cifras en porcentajes sobre el total, vemos que el crecimiento relativo se produce solamente en las salidas desde Bilbao hacia el resto del área metropolitana y hacia el resto de la 
CAV, y que es precisamente el resto de la CAV la que acoge los movimientos con origen tanto en el área metropolitana como en el resto de la CAV. Es decir, se produce una difusión amplia de los movimientos de salida, tanto desde el municipio de Bilbao, como desde el conjunto del A.M. hacia la CAV e incluso hacia fuera de la CAV.

Tabla 1. Movimientos Residencia/Trabajo. Relaciones Origen/Destino entre diferentes ámbitos.

a) año 1991

\begin{tabular}{|l|r|r|r|r|r|}
\hline O/D año 1991 & BILBAO & RESTO AM & RESTO CAV & FUERA CAV & Totales \\
\hline BILBAO & 91952 & 20326 & 6897 & 2637 & 121812 \\
\hline RESTO AM & 39461 & 133499 & 17355 & 6153 & 196568 \\
\hline RESTO CAV & 12433 & 178064 & 382121 & 15616 & 588234 \\
\hline
\end{tabular}

b) año 2001

\begin{tabular}{|l|r|r|r|r|r|}
\hline O/D año 2001 & BILBAO & RESTO AM & RESTO CAV & FUERA CAV & Totales \\
\hline BILBAO & 93440 & 28948 & 10217 & 3690 & 136295 \\
\hline RESTO AM & 47467 & 160075 & 26959 & 7273 & 241774 \\
\hline RESTO CAV & 14105 & 173003 & 515539 & 18853 & 721500 \\
\hline
\end{tabular}

Fuente: Eustat. Censos de 1991 y 2001. Elaboración propia (agregación).

La tabla 2 nos muestra las relaciones del A.M. de Bilbao con otras áreas externas específicas $^{6}$, con las que existe una mayor vinculación funcional. Algunas de estas áreas han estado ligadas tradicionalmente a Bilbao a través de la mano de obra industrial, como en el caso del valle del Nervión, y, en menor medida, del Ibaizabal. También son relaciones que atañen a la actividad industrial los movimientos con las áreas guipuzcoanas del Bajo y del Alto Deva, si bien, algo más debilitadas por la distancia, mientras que Mungia es un pequeño municipio industrial que ha intensificado las relaciones con Bilbao gracias a las mejoras de la accesibilidad, incrementando también su papel como municipio residencial. La zona denominada Costa tiene un carácter residencial, habiéndose intensificado esta función con el crecimiento demográfico experimentado en las dos últimas décadas del siglo XX por el municipio de Sopelana, como continuación del área residencial de la margen derecha de la ría de Bilbao. Finalmente, incluimos los movimientos origen/destino relativos a las otras dos capitales provinciales, Vitoria-Gasteiz y San Sebastián. En esa tabla podemos ver como se incrementan las relaciones con Vitoria-Gasteiz, y cuya causa más aparente es el estatus de capital de la Comunidad Autónoma del País Vasco que adquiere en este periodo. Sin embargo hay una pérdida de intensidad en las relaciones con San Sebastián.

6 Esta tabla no incluye toda la CAV sino una selección de áreas con mayor relación. La composición por municipios de estas áreas es la siguiente: Costa: formado por los municipios de Barrika, Gorliz, Plentzia, Sopelana y Urduliz; Nervión: formada por Llodio, Amurrio y Orozco; Mungia, solo el municipio de ese nombre; Ibaizabal medio, formado por Amorebieta y Durango; Bajo Deba: el municipio vizcaíno de Ermua, además de los guipuzcoanos de Eibar y Elgoibar; Alto Deba: los municipio guipuzcoanos de Bergara, Arrasate o Mondragón y Oñati; Vitoria-Gasteiz y San Sebastián son los municipios que corresponden con esas capitales. 
Hay que resaltar igualmente en este tramo temporal el aumento de las relaciones con Castro-Urdiales, en Cantabria, que se ha convertido en un enclave residencial de personas que trabajan en el A.M.B., si bien la fuente estadística utilizada aquí no nos permite obtener datos homologables a los presentados en la tabla. Utilizando algu-

Tabla 2. Movimientos de origen y destino del A.M. de Bilbao hacia y desde los entornos con mayores relaciones residencia/empleo en 1991 y 2001.

\begin{tabular}{|l|r|r|l|r|r|}
\hline \multicolumn{2}{|c|}{ Movimientos de entrada en el AM de Bilbao } & \multicolumn{2}{c|}{ Movimientos de salida del AM de Bilbao } \\
\hline Origen en & año 1991 & año 2001 & Destino en & año 1991 & año 2001 \\
\hline COSTA & 3076 & 6741 & COSTA & 1387 & 2375 \\
\hline NERVION & 1421 & 1754 & NERVION & 1943 & 2501 \\
\hline MUNGIA & 1190 & 2278 & MUNGIA & 1541 & 3103 \\
\hline IBAIZABAL MEDIO & 1455 & 2223 & IBAIZABAL MEDIO & 1793 & 3395 \\
\hline BAJO DEBA & 306 & 426 & BAJO DEBA & 575 & 558 \\
\hline ALTO DEBA & 224 & 142 & ALTO DEBA & 676 & 759 \\
\hline Vitoria & 1022 & 970 & Vitoria & 2107 & 3736 \\
\hline Donostia & 1139 & 484 & Donostia & 1041 & 852 \\
\hline
\end{tabular}

Fuente: Eustat. Censos de los años citados. Elaboración propia (agregación).

nos indicios ${ }^{7}$, podríamos estimar la cantidad de movimientos entre Castro-Urdiales y el A.M.B. en cifras comparables a las del área Costa de la tabla 2.

De los movimientos analizados aquí se concluye que ha habido una intensificación de la movilidad a escala regional, con el surgimiento de algunos enclaves (caso de Costa, en especial el municipio de Sopelana), o el aumento de la intensidad en la vinculación tanto residencial como laboral con áreas industriales. Se han intensificado asimismo los destinos en Vitoria, pero se han debilitado las relaciones residencia/trabajo con San Sebastián.

Por otro lado, es evidente el crecimiento de Castro-Urdiales, en Cantabria, y su relación funcional con el A.M.B. Pero es ésta una relación no simétrica en los movimientos residencia/trabajo, y cuya intensidad es difícil de medir ${ }^{8}$.

La vinculación meramente residencial con el área metropolitana permite cuestionar el carácter de subcentros de estas dos áreas de reciente crecimiento, ya que la definición de "subcentro" exige que organice áreas de niveles jerárquicos inferiores, y éste no es el caso de Sopelana (que gravita hacia Getxo), o el de Castro Urdiales (que funciona como una isla residencial y de esparcimiento de fines de semana). Tampoco cumple los requisitos de subcentro el municipio de Mungia, según los criterios que empleamos en el siguiente apartado, estando vinculado por su segundo destino, a Zamudio.

7 Un estudio del Gobierno Vasco (2007) estima que los movimientos origen/destino que relacionan la Comunidad Cántabra con la CAV son del orden de unos 30.000 diarios, en ambas direcciones, de los cuales un $40 \%$ tienen una motivación laboral. Cerca del $86 \%$ de estos movimientos son originados por Castro Urdiales, Laredo y la capital, Santander.

$8 \mathrm{Se}$ desconoce, en particular, cuantas personas empadronadas en Castro Urdiales que tienen su puesto de trabajo en el A.M. de Bilbao poseen otra residencia en el A.M. de Bilbao, es decir, si las situaciones censales se traducen realmente en movilidad, algo que es característico de áreas que mantienen el carácter de segunda residencia, y que pueden presentar patrones estacionales de movilidad: mucha movilidad en verano, poca en invierno; y también con un pulso semanal: movimientos de fines de semana. 


\section{CAMBIOS EN LA ESTRUCTURA DE SUBCENTROS A ESCALA METROPOLITANA}

Para la identificación de los subcentros del A.M.B hemos utilizado la técnica de las ligazones sucesivas, basadas en el concepto de estructura nodal que desarrollaron Nystuen y Dacey (1961), y que es bien conocida en las técnicas de análisis de flujos (Moreno Jiménez, 1980; Gutiérrez Puebla, 1985). Esta técnica se ha aplicado a las tablas de origen y destino disponibles para los años 1980, 1986, 1991, 1996 y 2001. No obstante, a efectos de simplificar las conclusiones, expondremos aquí los resultados de los años 1980, 1991 y 2001, que muestran de manera clara los cambios en la organización de los subcentros. La técnica se basa en la jerarquización de los municipios de acuerdo con el flujo externo que reciben, en este caso ese flujo lo denominamos "empleo atraído externo", consistente en el total de personas que entran a trabajar a ese municipio y que residen en municipios externos. Algebraicamente, se obtiene restando la cifra de la diagonal de la tabla origen/destino a la cifra total de los destinos laborales en cada municipio en cuestión. Es decir, el empleo atraído externo es el total de puestos de trabajo locales menos los puestos ocupados en dicho municipio por los propios residentes.

La figura 1 muestra la distribución rango-tamaño de los valores del empleo atraído externo recogidos en la tabla 3.

Figura 1. Distribución rango-tamaño del empleo atraído externo de los municipios del A.M. de Bilbao.

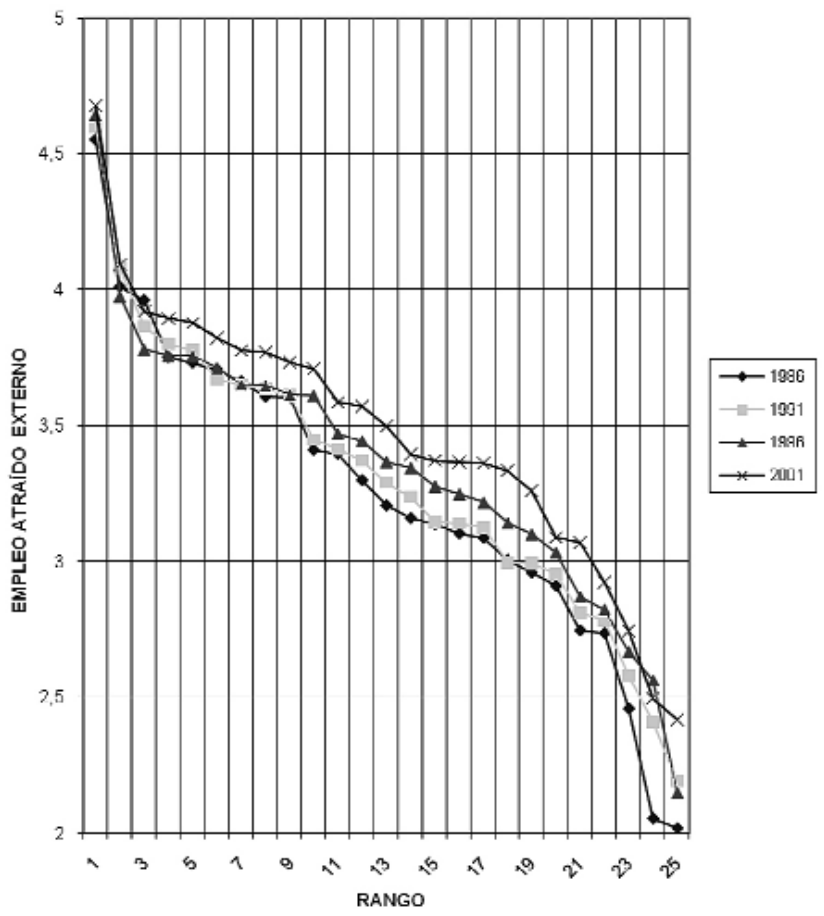

Fuente: Eustat: Censos de 1991 y 2001. Padrones 1986 y 1996. Elaboración propia. 
En esta figura se aprecia el crecimiento del empleo atraído externo a lo largo del periodo, en especial en los rangos intermedios, lo cual no evita que se siga manteniendo la primacía de Bilbao. Hay que subrayar que esta variable, que determina el rango de los centros para identificar los puntos terminales de la estructura nodal, incluye el empleo procedente de toda la CAV, menos el proveniente del propio municipio.

La estructura nodal se basa en la identificación, dentro de una matriz de flujos origen/destino, de los "puntos terminales". Un punto terminal se define como aquel municipio que dirige su principal flujo de salida hacia otro municipio de rango inferior. Es decir, siempre que el municipio de destino tenga un rango inferior en la lista ordenada, de más a menos, en el valor "empleo atraído externo". Una vez identificados los puntos terminales, se dibuja un esquema topológico uniendo cada municipio con aquel al que se dirige su mayor flujo externo, definiéndose así una estructura arborescente.

Al aplicar esta técnica a los datos del A.M.B. encontramos que para el primer destino sólo hay un punto terminal, que es el municipio de Bilbao, creando un árbol con muy pocas bifurcaciones en los años ochenta, y sin ninguna bifurcación en el año 2001, es decir, en esta última fecha todos los municipios aquí considerados, excepto Bilbao, obviamente, dirigen su principal flujo externo a este municipio. Debido a esta simplificación del árbol topológico correspondiente al primer destino, hemos considerado innecesario el representarlo gráficamente, pues puede imaginarse fácilmente un esquema semejante a las varillas de un paraguas confluyendo en el eje del bastón.

La tabla 3 recoge las cifras del empleo atraído externo para todos los municipios del área metropolitana, ordenadas según los rangos. Los mismos cambios en los rangos nos permiten ver los distintos "saltos" hacia arriba o hacia abajo dentro de la jerarquía en sucesivas fechas. Hay que señalar un hecho aparentemente contradictorio, y es que aunque hay un aumento generalizado del empleo atraído externo en todos los municipios, este aumento ha sido relativamente menor en Bilbao, que, sin embargo, recoge el destino principal de todos los municipios en el año 2001. Este hecho se justifica por el debilitamiento de algunos municipios intermedios que antes atraían más empleo, sobre todo empleo industrial. De los datos de la tabla 3 puede concluirse el estancamiento relativo de algunos municipios de la Margen Izquierda, a pesar de que en cifras absolutas ganan empleo atraído, pero descienden de rango en la jerarquía, y, en el caso de Sestao, de una pérdida de atracción de empleo externo en términos absolutos, mientras que hay un gran aumento del empleo atraído, así como de rango en los casos de los municipios de Zamudio, en el Txoriherri, por una parte, y de Leioa, en la Margen Derecha, por otra.

Para ver qué consecuencias han tenido estos cambios en la configuración de la estructura nodal metropolitana hay que proceder a analizar las ligazones sucesivas, y así, continuar el análisis iterando el procedimiento, definiendo el punto terminal correspondiente al segundo destino, que, en nuestro caso resulta más revelador, pues muestra un esquema de subcentros con ciertas características de permanencia en los años estudiados, así como algunos cambios significativos a lo largo del periodo estudiado. 
Tabla 3. Rangos de los municipios según el empleo atraído externo.

\begin{tabular}{|c|c|c|c|c|c|c|c|c|}
\hline Rango & municipio & 1986 & municipio & 1991 & municipio & 1996 & municipio & 2001 \\
\hline 1 & Bilbao & 35481 & Bilbao & 39461 & Bilbao & 43770 & Bilbao & 47467 \\
\hline 2 & Barakaldo & 10202 & Barakaldo & 11974 & Barakaldo & 9408 & Barakaldo & 12357 \\
\hline 3 & Sestao & 9111 & Sestao & 7295 & Sestao & 6014 & Zamudio & 8306 \\
\hline 4 & Basauri & 5633 & Basauri & 6289 & Getxo & 5705 & Getxo & 7813 \\
\hline 5 & Getxo & 5368 & Getxo & 6011 & Basauri & 5695 & Leioa & 7531 \\
\hline 6 & Erandio & 5074 & Erandio & 4683 & Leioa & 5135 & Basauri & 6634 \\
\hline 7 & Trapagaran & 4575 & Galdakao & 4441 & Erandio & 4472 & Erandio & 5969 \\
\hline 8 & Galdakao & 4026 & Leioa & 4318 & Trapagaran & 4420 & Sestao & 5863 \\
\hline 9 & Leioa & 3997 & Trapagaran & 4081 & Galdakao & 4102 & Galdakao & 5402 \\
\hline 10 & Portugalete & 2556 & Portugalete & 2802 & Zamudio & 4074 & Trapagaran & 5099 \\
\hline 11 & Santurtzi & 2471 & Santurtzi & 2578 & Portugalete & 2947 & Portugalete & 3849 \\
\hline 12 & Etxebarri & 1980 & Zamudio & 2338 & Santurtzi & 2770 & Santurtzi & 3717 \\
\hline 13 & Loiu & 1599 & Etxebarri & 1940 & Etxebarri & 2319 & Derio & 3150 \\
\hline 14 & Sondika & 1436 & Sondika & 1719 & Sondika & 2203 & Sondika & 2470 \\
\hline 15 & Derio & 1365 & Loiu & 1397 & Arrigorriaga & 1886 & Abanto & 2340 \\
\hline 16 & Arrigorriaga & 1261 & Derio & 1375 & Derio & 1767 & Arrigorriaga & 2312 \\
\hline 17 & Zamudio & 1215 & Arrigorriaga & 1329 & Abanto & 1645 & Loiu & 2286 \\
\hline 18 & Zaratamo & 1011 & Zaratamo & 990 & Loiu & 1385 & Etxebarri & 2153 \\
\hline 19 & Muskiz & 906 & Muskiz & 979 & Zaratamo & 1257 & Muskiz & 1815 \\
\hline 20 & Abanto & 810 & Abanto & 899 & Muskiz & 1077 & Zaratamo & 1220 \\
\hline 21 & Ortuella & 556 & Ortuella & 643 & Ortuella & 741 & Ortuella & 1171 \\
\hline 22 & Berango & 543 & Berango & 610 & Berango & 665 & Berango & 837 \\
\hline 23 & Lezama & 286 & Lezama & 380 & Lezama & 466 & Lezama & 554 \\
\hline 24 & Alonsotegi & 113 & Alonsotegi & 256 & Alonsotegi & 365 & Zierbena & 312 \\
\hline 25 & Larrabetzu & 104 & Larrabetzu & 155 & Larrabetzu & 141 & Larrabetzu & 261 \\
\hline 26 & Zierbena & $\mathrm{s} / \mathrm{d}^{*}$ & Zierbena & $\mathrm{s} / \mathrm{d}^{*}$ & Zierbena & $\mathrm{s} / \mathrm{d}^{*}$ & Alonsotegi & 209 \\
\hline
\end{tabular}

Fuente: Eustat. Elaboración propia (ver texto).

*datos incluidos en Abanto

Para el segundo destino aparece en la tabla de 1980 (basada en la citada Encuesta de Origen/Destino), y en 1986 una estructura de cuatro subcentros: Barakaldo, Basauri, Getxo y Loiu, que articulan cuatro áreas definidas por los subgrafos respectivos, y que corresponden a cuatro áreas funcionales que de pueden identificar con los nombres de Margen Izquierda, Ibaizábal-Nervión, Margen Derecha y Txoriherri. Estas mismas áreas ${ }^{9}$ estarán definidas según la estructura nodal correspondiente a la tabla origen/destino del año 2001, aunque los esquemas de organización interna han cambiado, tal como puede verse en la figura 2.

Estos cambios pueden resumirse en los siguientes. En primer lugar, en la Margen Izquierda se produce una reorganización de los flujos origen destino que lleva consigo una simplificación del árbol nodal. Así, en los años 1980, y prácticamente hasta el año 1991 había una cierta complejidad de relaciones debido a "escalones intermedios", en particular por el papel que desempeñaba Sestao como destino laboral (sede de parte de la factoría de Altos Hornos de Bizkaia así como de la Naval), y también por un papel menor

9 Margen Izquierda: incluye Abanto, Alonsotegi, Barakaldo, Muskiz, Ortuella, Portugalete, Santurtzi, Sestao, Trapagaran, y Zierbena; Margen Derecha: Berango, Erandio, Getxo, Leioa; IbaizabalNervión: Arrigorriaga, Basauri, Etxebarri, Galdakao, Larrabetzu, Zaratamo; Txoriherri: Derio, Lezama, Loiu, Sondika, Zamudio. 
de Portugalete como centro de empleo en servicios. En el año 2001, el árbol nodal queda totalmente centrado en Barakaldo, que también ha perdido mano de obra industrial, pero que empieza a destacar como el principal centro de servicios de la Margen Izquierda. Barakaldo reproduce así, para la Margen Izquierda, el eje del modelo de "varilla de paraguas" que Bilbao representa para el conjunto del A.M. como primer punto terminal.

En segundo lugar hay que destacar la organización durante este periodo del Txoriherri como subárea caracterizada casi exclusivamente como destino laboral. Se trata de un área en la cual emerge el municipio de Zamudio como centro principal, aunque, en este caso, hablar de centro quizá no sea lo más exacto ${ }^{10}$. De hecho, la expresión "Corredor del Txoriherri" es más descriptiva, pues se trata de un eje viario salpicado de polígonos industriales. La centralidad de Zamudio se debe a la localización en ese municipio del Parque Tecnológico, aunque el empleo no se concentre exclusivamente en ese enclave. Entre los años 1980 y 2001 los flujos residencia trabajo en esta área se van organizando jerárquicamente, ya que se trata de flujos de pequeña intensidad que fluctúan, a veces dibujando otras áreas, tal como muestra el mapa correspondiente al año 1991 en que Loiu es un "punto terminal" que atrae el flujo del municipio de Sondika. Sin embargo, el crecimiento de los puestos de trabajo en Zamudio, en la última década, hace que este municipio ocupe el tercer rango del A.M. el año 2001 en cuanto a empleo atraído externo, después de Bilbao y Barakaldo.

La estructura nodal de la margen derecha no experimenta cambios en este periodo, si bien habría que señalar que el municipio de Leioa llega a alcanzar una cifra de empleo atraído externo comparable a Getxo, el principal subcentro. Getxo ha destacado desde comienzos del siglo XX como principal núcleo residencial del área metropolitana, muy dependiente de Bilbao, donde trabaja cerca del $30 \%$ de los activos residentes de este municipio. El crecimiento residencial de Getxo se ha desbordado hacia otros municipios costeros próximos, especialmente, Sopelana.

El área de Ibaizabal-Nervión, llamada así por la confluencia aquí de esos dos ríos, apenas experimenta cambios, teniendo a Basauri como centro principal. Hay que señalar aquí que el descenso del empleo industrial en los municipios principales (Basauri y Galdakao) ha sido compensado por un crecimiento de los servicios, ya que en el término de Basauri se localizó el centro comercial metropolitano más antiguo del A.M.B, mientras que Galdakao acoge desde el año 1984 un hospital de la red pública de sanidad que tiene en la actualidad cerca de 1400 empleados. Galdakao ha surgido así como un segundo escalón dentro de esta área funcional, atrayendo los destinos de los municipios de Etxebarri y Larrabetzu ${ }^{11}$.

10 “Txoriherri” ("valle de los pájaros") es la denominación popular de un área tradicionalmente rural, aunque muy dependiente del municipio de Bilbao. De hecho, algunos municipios de esta zona, también conocida como Valle de Asua, estuvieron anexionados a Bilbao en los años 1960. Con anterioridad la dependencia funcional se estableció, en los años de posguerra, con la localización en Derio del Cementerio de Bilbao, y posteriormente del aeropuerto, cuya terminal se encuentra actualmente en el municipio de Loiu, pero cuyas pistas de aterrizaje y terrenos de servidumbre ocupan buena parte de los municipios de Loiu, Sondika, Derio y Zamudio.

11 Larrabetzu, aunque no pertenece a la cuenca fluvial del valle de Asua, se suele considerar dentro del llamado corredor del Txoriherri, sin embargo, se constata que su dependencia funcional en cuanto a los movimientos residencia/trabajo es de Galdakao. 
Figura 2. Estructura nodal del segundo destino para los años 1980, 1991 y 2001. Fuente: Ayuntamiento de Bilbao (1980) y Eustat: Censos de 1991 y 2001( Elaboración propia)

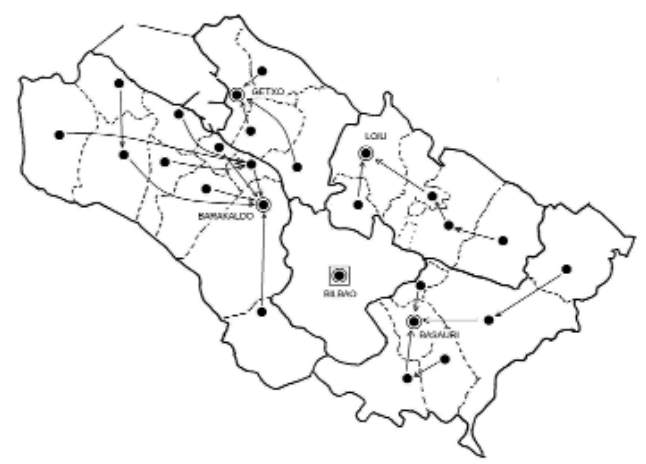

1991

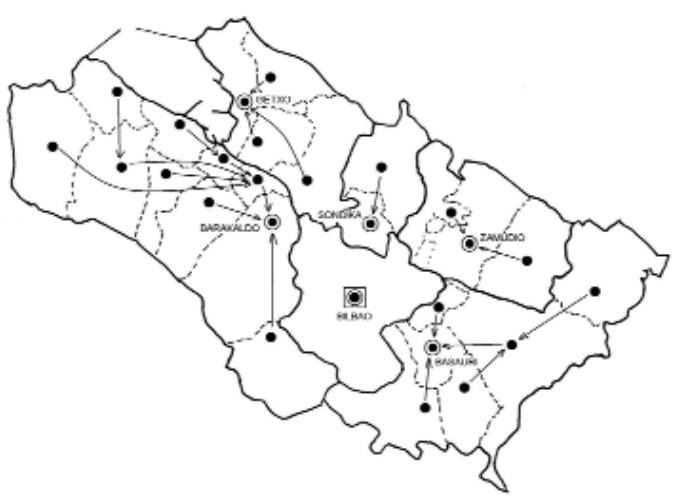

2001

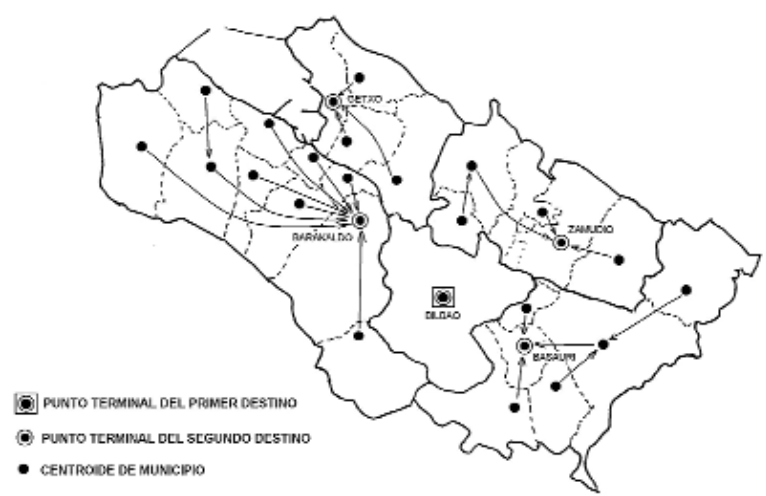

Fuente: Ayuntamiento de Bilbao (1980) y Eustat: Censos de 1991 y 2001( Elaboración propia) 
Para una mejor comprensión de los cambios en las estructuras nodales, añadimos la siguiente figura con los árboles topológicos.

Figura 3: Árboles topológicos correspondientes a las estructuras nodales de 1980, 1991 y 2001. 1980

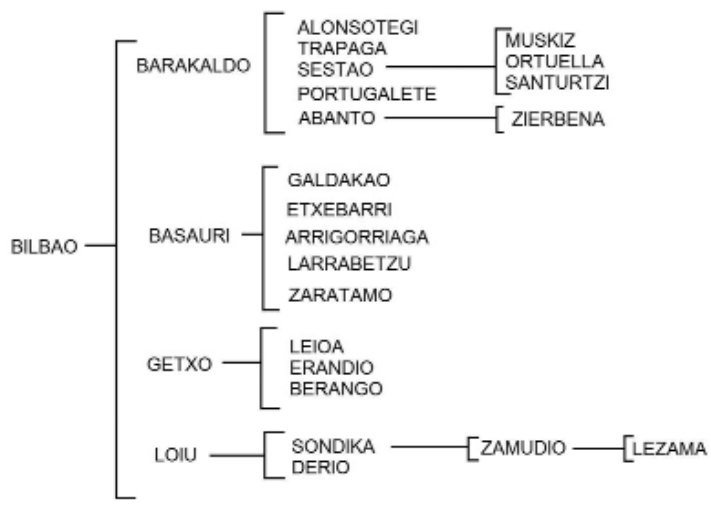

1991

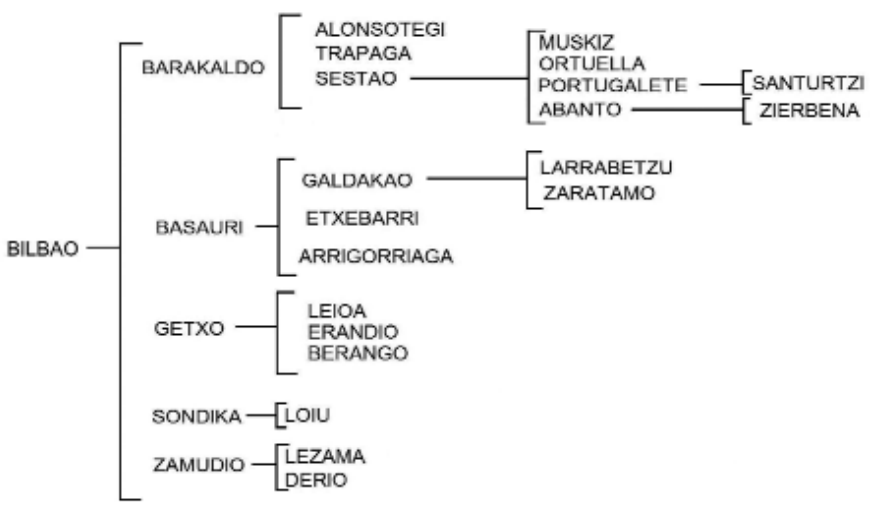

2001

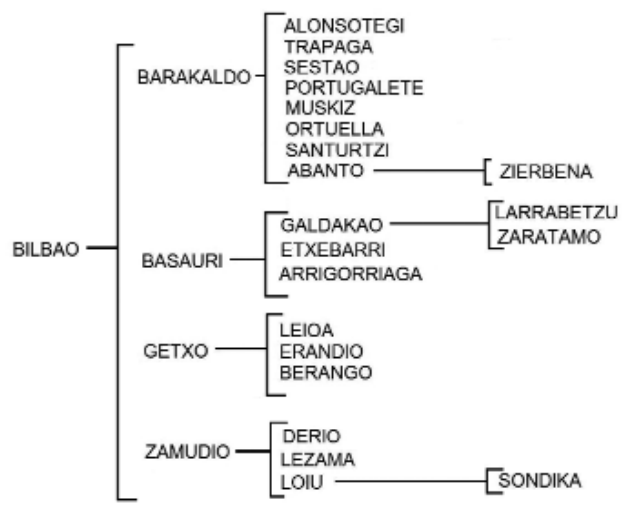

Fuente: Ayuntamiento de Bilbao (1980) y Eustat : Censos de 1991 y 2001( Elaboración propia)

Anales de Geografia 


\section{LAS CARACTERÍSTICAS DE LOS SUBCENTROS METROPOLITANOS}

A lo largo del periodo analizado aquí se van configurando una estructura de cuatro subcentros que organizan otras tantas áreas dentro del espacio metropolitano. En este apartado describimos las características de estos subcentros dentro del conjunto del área.

En la Margen Izquierda ha sido la pérdida de empleo industrial la que ha producido unas relaciones jerárquicas distintas a las de la etapa industrial, en la que algunos municipios como Barakaldo o Sestao acogían la mayor parte de los destinos laborales, principalmente en industrias situadas en las marismas y en las vegas fluviales: la empresa Altos Hornos de Vizcaya contaba con grandes instalaciones situadas en los terrenos de la terraza baja de la Ría de Bilbao, tanto en Barakaldo como en Sestao, así como en la vega del río Galindo (factorías de laminación de la misma empresa). Junto con esta empresa, la construcción naval, en Sestao era otro destino laboral destacable. La desaparición de Altos Hornos de Vizcaya ha dejado vacante suelo que en gran medida se ha convertido en residencial, aunque hay también una cierta continuidad de las actividades industriales. En los terrenos de esta empresa, en Sestao, se ha localizado una miniacería (la empresa ACB) que da empleo a unos 400 trabajadores. La miniacería y los astilleros, reconvertidos después de los años 1980 , son un recuerdo vivo de la industria tradicional de estas localidades. Desde comienzos de los años 1990 se ha considerado, en los documentos de planificación metropolitana, las grandes superficies abandonadas por la industria como "áreas de oportunidad", que coinciden en gran medida con las superficies de viejas marismas y terrazas fluvio-marinas del valle del bajo Nervión ${ }^{12}$.

Pero el suelo industrial liberado, en especial, en Barakaldo, se ha destinado a la construcción de viviendas y a grandes infraestructuras de servicios, en especial, grandes superficies comerciales. Primero fue Max Center, un centro de estilo "mall", en Barakaldo, y posteriormente Mega Park, un gran parque formado de grandes superficies, ocupando suelo anteriormente destinado a usos industriales; más recientemente, la localización en la vega de Galindo de la feria de muestras de Bilbao, bajo el nombre comercial BEC (Bilbao Exhibition Center). Aún está en proceso de conversión el suelo de la factoría Fertiberia, en situación de traslado, cuyo destino será residencial. De esta manera Barakaldo se ha convertido en el principal centro de servicios de la Margen Izquierda, y en el segundo centro metropolitano, por detrás de Bilbao, pero que ahora destaca por su carácter residencial por encima del carácter laboral.

Barakaldo absorbe el segundo destino de todos los municipios del área de la Margen Izquierda, ya que se han debilitado los destinos hacia Sestao. Barakaldo funciona como un eje de paraguas respecto a resto de los municipios de la Margen Izquierda.

12 Avance del Plan Territorial Parcial del Bilbao Metropolitano, de 1993-94. Bilbao. Diputación Foral de Bizkaia. 
En otras antiguas zonas industriales se han detectado cambios semejantes en cuanto a los movimientos residencia-trabajo, como en Asturias Central, si bien allí el esquema espacial de centros es bien distinto, con la debilitación de las cuencas mineras (Blanco Fernández y Carrero Roa, 2001).

Por otro lado, dentro de esta área están surgiendo nuevas localizaciones de destinos laborales, sobre todo en polígonos de reciente implantación, como en Trapaga y en Ortuella, ocupando suelo vacante de la zona minera, y va a ser en esta zona donde, en un futuro próximo, aumente el suelo industrial y la localización de destinos laborales.

En el área de la Margen Derecha el esquema de la estructura nodal se mantiene a lo largo de todo el periodo estudiado, teniendo a Getxo como subcentro. Aquí hay que señalar el carácter residencial de este municipio, muy dependiente de los puestos de trabajo en Bilbao. A pesar de su crecimiento demográfico durante este periodo. Getxo no ejerce una atracción de destinos laborales comparable a Barakaldo, ocupando así el tercer puesto en la jerarquía de centros. Dentro de la Margen derecha hay que destacar la creciente importancia de Leioa y Erandio como destinos laborales, también en conexión con el Txoriherri. En Leioa se localiza un campus universitario, perteneciente a la Universidad del País Vasco (UPV/EHU) que fue creado como campus de la Universidad Autónoma de Bilbao en 1970.

En el área de Ibaizabal-Nervión el cambio más reseñable es la pérdida relativa de rango de Basauri respecto a la atracción de empleo externo, si bien, en cifras absolutas aumenta su atracción. En esta área aparece como un segundo escalón Galdakao, que capta el segundo destino de los municipios de Larrabetzu y Zaratamo.

Pero el fenómeno más destacable del periodo ha sido el surgimiento del Txoriherri como destino laboral metropolitano, articulado ahora en torno al municipio de Zamudio. Esta área fue considerada en el pasado como zona de posible expansión residencial de Bilbao, llegando a convocarse en los años 1960 un concurso internacional para la urbanización residencial del valle de Asua. Su orientación hacia la industria se fue acentuando, en una primera etapa, por la penetración de algunas instalaciones fabriles por el valle del río Asua, en terrenos de Erandio, y más adelante por la localización del aeropuerto de Sondika, y su ampliación hasta el actual aeropuerto, cuya terminal está en terrenos del municipio de Loiu. La localización del Parque Tecnológico de Zamudio señaló la zona como área de industrias tecnológicas en ese enclave, pero más adelante, como área de industrias más comunes, almacenaje, centros logísticos, y también de localización de empresas de servicios (actividades rutinarias de la banca, consultoría, etc.).

Como podemos ver los cuatro subcentros metropolitanos de Bilbao tienen unas características muy distintas, y articulan áreas que se diferencian entre sí en el balance entre la población residente y el empleo. Estas diferencias están recogidas en la tabla siguiente. 
Tabla 4. Empleo residente y atracción de empleo (destinos laborales) en las subáreas metropolitanas

\begin{tabular}{|c|c|c|c|c|}
\hline Año 1991 & $\begin{array}{l}\text { Destinos laborales } \\
\text { Metropolitanos (a) }\end{array}$ & $\begin{array}{l}\text { Destinos laborales } \\
\text { CAV (b) }\end{array}$ & $\begin{array}{l}\text { Empleo } \\
\text { Residente (c) }\end{array}$ & Saldo (c-b) \\
\hline Bilbao & 131413 & 143846 & 121812 & -22034 \\
\hline Margen Izquierda & 65135 & 67207 & 85219 & 18012 \\
\hline Margen Derecha & 29868 & 31686 & 43637 & 11951 \\
\hline Txoriherri & 9381 & 10320 & 8160 & -2160 \\
\hline Ibaizabal-Nervión & 29215 & 31463 & 33247 & 1784 \\
\hline Año 2001 & $\begin{array}{l}\text { Destinos laborales } \\
\text { Metropolitanos (a) }\end{array}$ & $\begin{array}{l}\text { Destinos laborales } \\
\text { CAV (b) }\end{array}$ & \begin{tabular}{|l|} 
Empleo \\
Residente (c)
\end{tabular} & Saldo (c-b) \\
\hline Bilbao & 140907 & 155012 & 135491 & -19521 \\
\hline Margen Izquierda & 70698 & 73698 & 97601 & 23903 \\
\hline Margen Derecha & 37857 & 41469 & 55657 & 14188 \\
\hline Txoriherri & 19216 & 21997 & 6998 & -14999 \\
\hline Ibaizabal-Nervión & 32304 & 35839 & 39467 & 3628 \\
\hline
\end{tabular}

Fuente: Eustat. Elaboración propia (agregación)

Estos cambios apuntan a un nuevo modelo de localización de la mano de obra a escala metropolitana, en el cual es el municipio de Bilbao el que continúa teniendo la mayor atracción del empleo externo, si bien con cierta disminución relativa respecto a la población residente, y donde, por otra parte, aparecen nuevos "nichos" de empleo en las áreas periféricas, pero sin que lleguen a constituir propiamente subcentros metropolitanos, como el caso del Txoriherri, debido a su carácter casi único de lugares laborales, con muy poca importancia de la función residencial.

Podemos discernir de manera simple el papel que desempeña cada uno de los municipios que actúan como subcentros en la estructura nodal de los movimientos residencia/trabajo, viendo el grado de reciprocidad origen/destino que cada uno de ellos establece con Bilbao, el municipio central, en la tabla 5.

Tabla 5. Movimientos entre los subcentros y Bilbao. Año 2001.

\begin{tabular}{|l|l|l|l|}
\hline Municipios & $\begin{array}{l}\text { Movimientos con destino en Bilbao } \\
\text { (a) }\end{array}$ & $\begin{array}{l}\text { Movimientos con origen en Bilbao } \\
\text { y destino en cada municipio } \\
\text { (b) }\end{array}$ & $\begin{array}{l}\text { Reciprocidad } \\
\text { (a/b) }\end{array}$ \\
\hline Barakaldo & 8122 & 4544 & 1,79 \\
\hline Getxo & 9841 & 2119 & 4,64 \\
\hline Basauri & 4158 & 2905 & 1,43 \\
\hline Zamudio & 246 & 3164 & 0,11 \\
\hline
\end{tabular}

Fuente: Eustat. Elaboración propia (agregación).

Como puede observarse hay una mayor reciprocidad entre los municipios de Barakaldo y Basauri, que envían y reciben mano de obra hacia Bilbao y desde Bilbao, frente a los municipios de Getxo (que fundamentalmente envía a Bilbao), y a Zamudio (que sobre todo recibe mano de obra desde Bilbao). 


\section{CAMBIOS EN LA MOVILIDAD: EL DESCENSO DE LA FRICCIÓN DE LA DISTANCIA}

Con los datos de las tablas origen/destino hemos analizado el cambio cuantitativo en la resistencia o fricción de la distancia de los movimientos, medido a través del parámetro de un modelo potencial inverso, tal como se muestra en el apéndice "a" de fórmulas de este artículo. El parámetro mide cómo desciende el número de viajes conforme aumenta la distancia al origen de los mismos.

Hay que aclarar que este parámetro se estima, en este caso, en la escala intrametropolitana, no teniendo en cuenta los movimientos que van más allá de los límites del área estudiada. Esto influye sin duda en los valores de los parámetros obtenidos empíricamente (el conocido problema de la unidad espacial modificable), pero aún así, estas estimaciones tienen un valor comparativo de interés, y permiten llegar a conclusiones.

Dado que un estudio de la accesibilidad a escala metropolitana hubiera sido muy complejo, debido a la variedad de modos de transporte (Metro, ferrocarril de cercanías, tranvía, autobuses, automóvil, movimientos peatonales, ascensores, etc.) hemos tomado como referentes la matriz de distancias por carretera entre los centros de los municipios. A partir de correlaciones lineales hemos obtenido los parámetros de fricción para los movimientos con origen en el conjunto del área y en cada uno de los municipios. Los parámetros para el conjunto del A.M. se muestran en la tabla 6.

Tabla 6. Parámetro de fricción de la distancia (ß) para las tablas Origen Destino.

\begin{tabular}{|c|c|c|c|}
\hline Año & Intersección & Pendiente $\beta$ & Correlación \\
\hline$* 1980$ & 5,02 & $-2,68$ & $-0,64$ \\
\hline 1991 & 3,45 & $-1,94$ & $-0,59$ \\
\hline 1996 & 3,37 & $-1,80$ & $-0,56$ \\
\hline 2001 & 3,49 & $-1,74$ & $-0,57$ \\
\hline
\end{tabular}

Fuente: Encuesta de 1980 (Ayuntamiento de Bilbao), censos de 1991 y 2001, padrón de 1996 (Eustat). Elaboración propia.

* El alto valor de la intersección en 1980 se debe a que la fuente utilizada maneja una cifra correspondiente al total de movimientos (no sólo residencia/trabajo). Sin embargo, consideramos válida para esa fecha la cifra del parámetro de la pendiente.

La disminución del valor del parámetro en términos absolutos se produce tanto a escala del conjunto de la metrópoli como en cada uno de los municipios. Si bien, como se sabe, es muy difícil hacer una interpretación social, o comportamental de los cambios en este parámetro a escala de ciertos agregados, como la escala municipal, en los que la composición social o profesional puede ser muy diversa en relación con la movilidad. El aspecto comportamental se detecta cuando se aplica este tipo de índices a colectivos con características sociodemográficas semejantes, por ejemplo: ancianos, mujeres de ciertas edades y profesiones, grupos de rentas altas que viven en enclaves residenciales lejos de los lugares de trabajo, y que presentan pautas de movilidad similares.

Aún así, hemos encontrado un cierto contraste entre los valores de fricción aplicados a los datos municipales de 1980 y los posteriores. En el caso de la distribución de los valores de fricción para 1980 encontramos que son muy altos, por encima de 
la media, en los municipios de la Margen Izquierda, que tienen sus destinos laborales muy próximos, sobre todo en municipios con mucha población como Barakaldo, Portugalete, Sestao y también en Trapagaran y Muskiz. En los datos de los años 1991, 1996 y 2001, estos municipios disminuyen considerablemente los valores de fricción, mientras que los valores más altos, al final del periodo, corresponden a municipios más pequeños en cuanto a población y que a su vez recogen cifras relevantes de empleo atraído externo: municipios tales como Derio, Erandio, Galdakao, Etxebarri, Sondika o Zamudio tienen valores por encima de la media.

En cuanto a las distancias medias recorridas, siempre a escala intra-metropolitana, y estimadas con los datos de las tablas y la matriz de distancias, se constata un aumento progresivo de la distancia media recorrida, es decir, la que separa el domicilio del trabajo, con las cifras de 6,29 kilómetros, para el año 1980, de 6,60 para 1991, de 6,68 para 1996 y de 6,77 para el año 2001. Estas cifras deben ser comparadas, obviamente, con otras obtenidas mediante encuestas a individuos que revelen las distancias reales y los distintos medios de transporte empleados. Así, para el año 2005, un estudio del Gobierno Vasco daba una cifra media del movimiento diario de 21,58 kilómetros (sumando los viajes de ida y vuelta) para Bilbao (Oteus, 2005). Esta movilidad incluye todos los motivos de viaje, y también, lógicamente, la movilidad hacia fuera de la metrópolis. Pero como cifra media tampoco es muy ilustrativa, pues los movimientos descienden de acuerdo con funciones matemáticas negativas (ya sean lineales, potenciales o exponenciales) desde los orígenes. Si comparamos nuestras estimaciones con las cifras de la tabla 1, podremos afirmar que la cifra de $6,60 \mathrm{Km}$ de distancia media en 1991 es válida para el 89,6\% de los movimientos que tienen su origen en el AM de Bilbao, y la de 6,77 del año 2001 es válida para el $82,27 \%$ de los movimientos con origen en la misma área.

\section{ANÁLISIS DEL SISTEMA A TRAVÉS DEL TIEMPO. LOS ÍNDICES DE ENTROPÍA}

La idea de entropía fue introducida en el estudio de los movimientos origen/destino en los años 1960, como un perfeccionamiento de los modelos de gravedad para la predicción de los flujos, dadas ciertas condiciones: número total de personas que se desplazan, fricción de la distancia, y coste total de los viajes implicados en el sistema. Estos modelos, llamados de "maximización de la entropía" se extendieron, en particular a través del trabajo de Wilson (1970). Los modelos servían para estimar una tabla completa de movimientos origen/destino de acuerdo con las condiciones señaladas arriba, y podían restringirse, bien al total de los movimientos, o solamente al total de los orígenes, $o$ solamente al total de los destinos, o bien tanto a los orígenes como a los destinos, dependiendo del conocimiento de los datos empíricos de la interacción (constantes de proporcionalidad, parámetros de fricción de la distancia, en especial).

La entropía medida dentro de un sistema nos indica su grado de organización, o si se quiere, la comparación del estado real del sistema en un momento dado, con la situación de máximo desorden. En nuestro caso, la situación de máximo desorden se produciría si todos los movimientos $\mathrm{T}_{\mathrm{ij}}$ entre los lugares de origen $\mathrm{i} y$ un destino $\mathrm{j}$ fueran exactamente iguales en magnitud absoluta. 
Los valores netos de los índices de entropía para una tabla origen-destino nos indican la tendencia del sistema: si aumentan, nos indican una mayor interacción entre los lugares y una tendencia hacia un mayor "desorden", en el sentido que se hace menos predecible, desde el punto de vista estadístico, adivinar a priori cuál va ser el destino de un movimiento individual con origen en un lugar i. Si, por el contrario, el índice disminuye, supone que hay una tendencia a una mayor concentración de los movimientos en algunos orígenes y/o destinos determinados.

Dado que los índices de entropía dependen del número de orígenes y destinos que se considere en un sistema (es decir, del "grado de resolución") es mejor, con propósitos comparativos, convertir esos datos en índices relativos, conocidos como índices de redundancia, que pueden variar entre los valores 0 y 1 , siendo el valor 0 el correspondiente a la entropía máxima y 1 un valor teórico máximo en el caso de que la entropía fuera igual a cero, que en el ejemplo de los movimientos aquí tratados sólo se produciría si todos los movimientos se produjeran únicamente entre dos zonas o lugares i y j (vid. apéndice de fórmulas b).

Otra ventaja que tienen los índices de entropía, cuando una variable es bidimensional, como en nuestro caso, ya que los movimientos origen/destino tienen dos subíndices, es que nos permite ver en qué medida una de las dos dimensiones condiciona la distribución total de la entropía, lo que se conoce como ley de descomposición de la entropía, o entropía condicionada.

Finalmente, hay que considerar que los índices de entropía son, en definitiva, índices de diversidad, y que un lugar concreto dentro de un sistema de movimientos origen/destino puede ser clasificado de acuerdo con su diversidad de orígenes y de destinos, y que ambos índices nos revelan el papel que desempeñan en la interacción dentro del sistema, en nuestro caso, respectivamente, las características residenciales y las características como lugar de trabajo dentro del contexto metropolitano. Como índices de diversidad suponen una mejora de las habituales comparaciones numéricas basadas en el saldo residencia/empleo, como las que hemos utilizado en el apartado 4, o las que se han utilizado en otros estudios (Feria, 2010) ya que la diversidad alude tanto al número de orígenes y/o destinos desde y/o hacia un centro, como a su composición probabilística. Así, un grado de diversidad alta implica un mayor carácter central. La diversidad alta en cuanto a los orígenes desde un municipio mide el carácter centrífugo del municipio en cuestión, mientras que la diversidad alta en cuanto a destino, mide el carácter centrípeto.

En este estudio hemos utilizado el índice de entropía de Shannon y Weaver ${ }^{13}$, y lo hemos aplicado en tres niveles distintos: en primer lugar, a la totalidad de la tabla

13 Los índices de entropía se utilizan como medidas de la desigualdad o la diversidad en los sistemas, y como medidas de la cantidad de información. El índice de Shannon y Weaver se origina en la teoría de la información (Shannon y Weaver, 1948), pero llega a utilizarse en campos muy diversos como la ecología, la economía, etc. Existen índices alternativos, que dan a la entropía máxima un valor igual a cero (índice de Theil). Consideramos aquí más adecuado el uso del índice de Shannon y Weaver, ya que la magnitud aumenta con el tamaño urbano, y por ello es más adecuado para representar fenómenos jerárquicos, dado el carácter lognormal que tienen este tipo de distribuciones. Con propósitos comparativos utilizamos los índices recíprocos de entropía, la redundancia, cuyo valor varía entre 0 y 1 . 
origen/destino. En segundo lugar, a la totalidad de los orígenes y a la totalidad de los destinos, para identificar el papel que desempeñan, respectivamente, la localización de la residencia y la localización de los lugares de empleo dentro del sistema, y, finalmente, a los datos de cada municipio, como medidas de diversidad respectivamente de las salidas (es decir, a cuántos lugares y en qué proporciones se dirigen a trabajar los residentes de un determinado municipio), y a las llegadas (es decir, desde cuántos lugares y en qué proporciones vienen las personas que tienen su lugar de trabajo en un determinado municipio). Las fórmulas de entropía y redundancia se recogen en el apéndice $\mathrm{b}$ de fórmulas al final del artículo.

La tabla 7 recoge los valores de los índices aplicados a cuatro tablas de este periodo. Dada la carencia de los destinos desde Bilbao en el año 1986 no se ha utilizado la tabla origen/destino correspondiente a esa fecha.

Tabla 7. Valores de los índices de entropía y redundancia para las tablas origen/destino.

\begin{tabular}{|r|r|r|r|r|r|r|}
\hline Año & $\begin{array}{l}\text { Hij } \\
\text { (Entropía Total) }\end{array}$ & $\begin{array}{l}\text { Ho } \\
\text { (orígenes) }\end{array}$ & $\begin{array}{l}\text { Hd } \\
\text { (destinos) }\end{array}$ & $\begin{array}{l}\text { Rij } \\
\text { (Redundancia Total) }\end{array}$ & $\begin{array}{l}\text { Ro } \\
\text { (orígenes) }\end{array}$ & $\begin{array}{l}\text { Rd } \\
\text { (destinos) }\end{array}$ \\
\hline * 1980 & 4,963 & 2,756 & 2,735 & 0,459 & 0,399 & 0,403 \\
\hline 1991 & 5,202 & 3,124 & 2,964 & 0,447 & 0,335 & 0,369 \\
\hline 1996 & 5,469 & 3,156 & 2,979 & 0,418 & 0,329 & 0,366 \\
\hline 2001 & 5,649 & 3,223 & 3,159 & 0,399 & 0,314 & 0,328 \\
\hline
\end{tabular}

Fuente Ayuntamiento de Bilbao (1980) y Eustat (1991 a 2001). Elaboración propia.

*El año 1980 sólo se consideran 24 municipios, ya que con posterioridad se producen dos desanexiones (Alonsotegi y Zierbena, de los municipios de Barakaldo y Abanto, respectivamente). Como ya se ha indicado, el carácter de la tabla del año 1980, que recoge movimientos de ida y vuelta hace que no haya contraste numérico entre los valores de los orígenes y destinos de ese año (2,756 y 2,735 para las entropías y 0,399 y 0,403 para las redundancias). Si es consistente con el proceso evolutivo la cifra de la entropía total.

Los índices presentados en esta tabla nos indican que, al aumentar la entropía, estamos dentro de una etapa de difusión de la movilidad, en la cual, según muestran los valores de la redundancia, se produce un descenso de este índice de un $6 \%$, lo que indica una tendencia hacia un mayor "desorden" de los movimientos.

En cuanto al distinto papel de los orígenes y los destinos, encontramos que es la localización de los lugares de trabajo la que es más desigual, es decir más heteroprobable, o si se quiere la que "niega" la entropía organizando de una manera más jerárquica el sistema. No obstante, dentro de los años estudiados aquí, parece que esta diferencia en los papeles de la localización de la residencia y la localización de los lugares de trabajo se va atenuando. Es posible que estas diferencias se deban a los mecanismos de competencia implícitos en la dinámica de la evolución de los lugares de residencia que sigue, o depende, de la dinámica del surgimiento de los lugares de trabajo (nuevas localizaciones de empleo metropolitanas).

La evolución de los datos de entropía de orígenes y destinos de cada municipio sólo la hemos considerado para las fechas de 1991 y 2001, debido a la mayor adecuación de los datos. Entre esas dos fechas aumenta de manera significativa la entropía (diversidad) de los orígenes en algunos municipios que incrementan su carácter 
residencial, así, de mayor a menor: Leioa, Abanto, Arrigorriaga, Berango, Etxebarri y Getxo, mientras que disminuyen considerablemente (a causa, sin duda, de pérdida de población activa) los municipios de Basauri, Sestao, Barakaldo y Portugalete. En cuanto a la entropía de los destinos (es decir la diversidad de los lugares de la gente que llega a trabajar a un municipio) aumentan considerablemente en este periodo los índices de Zamudio, Leioa y Derio, mientras que disminuyen las de los municipios industriales de Sestao, Basauri y Barakaldo.

Es, lógicamente, la relación entre la diversidad de los orígenes y la diversidad de los destinos la que nos define el papel que desempeña cada municipio dentro del sistema. La figura 4 representa el gráfico de regresión entre las entropías de los destinos (variable dependiente) y las de los orígenes (variable dependiente) para el año 2001. En dicho gráfico, y con trazo oscuro se representa la línea de regresión, y con trazo fino, la bisectriz del cuadrante, que indica la igualdad de los dos índices de entropía. Como podemos apreciar, la línea de regresión está por debajo de la línea de igualdad, indicando la tendencia estadística a valores más altos de los orígenes.

Figura 4. Gráfico de dispersión de las entropías de los orígenes y los destinos.

\section{Entropías}

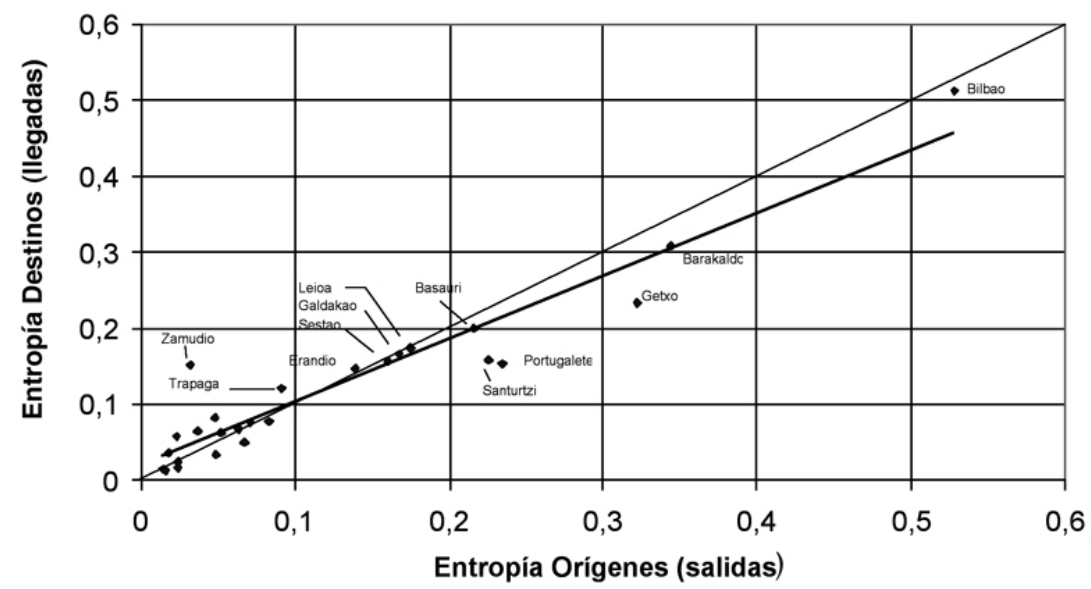

Fuente: Eustat. Censo de 2001.Elaboración propia.

La posición dentro de este gráfico de los municipios identificados como puntos terminales de la estructura nodal del área metropolitana nos indica que, salvo el caso de Getxo, casi todos ellos están caracterizados por unos valores altos en la diversidad de los destinos, además de los residuos positivos en la relación orígenes/destinos, destacando especialmente el caso de Zamudio. La línea de regresión separa claramente una división funcional, indicando los tres municipios con sesgo residencial de Getxo, Portugalete y Santurtzi, y, por otro lado a los identificados con los valores de residuos más altos de entropía de los destinos: Zamudio y Trapaga. Ello nos indica que los valores de la entropía son sensibles a otros indicadores jerárquicos como 
la población o el empleo total, y, lo que es más importante, a los atributos de origen y destino que en la vieja teoría de interacción eran denominados: impulsión desde los orígenes, atracción de los destinos, y existencia de oportunidades intermedias.

\section{CONCLUSIONES}

A lo largo de las dos décadas estudiadas aquí se constata un aumento generalizado de la movilidad dentro y hacia fuera del área metropolitana, con las características estructurales de disminución de la fricción de la distancia, incremento de los valores de la entropía de las tablas origen/destino, aumento de las distancias medias de los viajes, como una característica que es común en muchos sistemas metropolitanos.

Estos cambios no impiden ver las permanencias en algunos rasgos: constancia en las jerarquías, número de subcentros y subáreas y rasgos de dependencia con respecto al municipio central de Bilbao, permanencias que hemos identificado en este estudio.

Hay que subrayar que el aumento de la movilidad no se traduce aquí en el surgimiento de una estructura policéntrica nueva, ya que, si bien algunos subcentros aumentan su importancia relativa (simplificación de las estructuras nodales, como en el caso de Barakaldo en la Margen Izquierda), lo hacen por un debilitamiento relativo de la atracción del empleo en niveles inmediatamente más bajos. Por el contrario, la localización de algunos servicios metropolitanos en municipios de tercer nivel (caso del Hospital en Galdakao) puede producir un incremento de la centralidad en núcleos inferiores, en ese caso en competencia con el subcentro de Basauri.

Se constata, igualmente, las diferentes características funcionales y residenciales de los subcentros metropolitanos, que no pueden ser equiparables entre sí, ni alcanzan un nivel relevante de competencia con el municipio central de Bilbao. Así, de acuerdo con la reciprocidad de los movimientos residencia/trabajo, existe una integración bipolar entre Bilbao y Barakaldo, por una parte y entre Bilbao y Basauri, por otra, sin embargo, con Getxo las relaciones son más asimétricas, predominando los movimientos desde Getxo hasta Bilbao. Un signo diferente es la relación bipolar Bilbao/Zamudio en la cual este último municipio tiene un carácter predominante de destino laboral.

Cabría reflexionar, en este sentido, desde un doble punto de vista. Desde el punto de vista teórico, es necesario reflexionar en los mecanismos que sostienen las primeras "bipolaridades" que generan los esquemas policéntricos, y cómo evolucionan bajo ciertas condiciones: cambios en la movilidad, y en las condiciones de los mercados de trabajo y de vivienda, y también en los aspectos controlados por la planificación: las restricciones de los usos del suelo.

En el caso del A.M.B. hay ciertos rasgos que se mantienen desde sus orígenes históricos: las bipolaridades Bilbao/puerto; Bilbao/zona minero-industrial; Bilbao/zona residencial segregada (Getxo), y cuyos rasgos se mantienen a pesar de los cambios postfordistas. El esquema de cuatro subcentros, aunque no es tan nítidamente percibido por la población es, en buena medida, el resultado de la evolución de una estructura previa: Bilbao/zona industrial (Barakaldo); Bilbao/zona industrial de la confluencia Nervión-Ibaizabal y Bilbao/área residencial de la burguesía (Getxo y Margen Derecha). 
Una de las razones para que se mantenga el esquema jerárquico aquí mostrado en el área metropolitana de Bilbao puede estribar en el carácter compacto que tiene este espacio urbano en el cual las infraestructuras de transporte público siguen favoreciendo la centralidad de Bilbao. Estamos de acuerdo con otros autores (García Palomares y Gutiérrez Puebla, 2007) en que los espacios compactos favorecen más la movilidad sostenible, siendo Bilbao un ejemplo comparable a las grandes áreas metropolitanas europeas al tener una cuota alta de uso del transporte público, y que además, se incrementa en este periodo. Algunos estudios sobre transporte han subrayado la relación que existe entre la intermodalidad que se da en espacios compactos metropolitanos y los costes de transporte por habitante, siendo, dentro de la C.A.V. los menores costes los correspondientes al A.M. de Bilbao (Leber, 2008; Murga, 2010).

Los cambios en la fricción de la distancia nos revelan el desplome de mercados locales de trabajo que operaban a corta distancia, en particular, en la zona industrial de la Margen Izquierda del Nervión. En los nuevos destinos laborales se crean otros mercados locales de proximidad, aunque con menos intensidad en la fricción: así, Derio, Sondika y Zamudio en el Txoriherri; Erandio, en la Margen Derecha (pero también con conexión con el Txoriherri), y Galdakao y Etxebarri en la confluencia Nervión-Ibaizabal.

Las diferencias entre las distribuciones estadísticas de los orígenes y destinos, vistos en una secuencia evolutiva a través de los índices de entropía señalan una dinámica distinta para la distribución espacial del empleo y la distribución espacial de los residentes. Esas mismas diferencias, a escala de municipios individuales, identifican el diferente papel de cada uno de ellos dentro del sistema jerárquico, y ayudan a comprender los cambios estructurales.

Hay que señalar que el crecimiento de nuevos destinos laborales dentro del área metropolitana para actividades económicas, se ha fomentado en forma de polígonos industriales, o de polígonos para actividades terciarias, en la cual se proyectan nuevos destinos en áreas muy mal conectadas con la red de transporte público (fundamentalmente metro y ferrocarril), y el caso del extraordinario crecimiento del Txoriherri es una muestra de ello ${ }^{14}$. Esto es solo un reflejo de cómo la planificación de las infraestructuras de transporte va por detrás de la planificación urbana y de las nuevas realidades residenciales.

Estas pautas parecen continuar dentro de la planificación vigente, y así, en el Plan Territorial Parcial del Bilbao Metropolitano (2006) ${ }^{15}$, se señala como meta un reequilibrio espacial estratégico de las actividades económicas respecto a la residencia para favorecer la movilidad sostenible, y, en ese sentido plantea dedicar un $15 \%$ del nuevo

14 En el momento de revisar este trabajo se ha anunciado el estudio del proyecto de línea de metro hasta el Parque Tecnológico de Zamudio, cuya posible prolongación podría alcanzar el aeropuerto (Diario El Correo, 22-10-10). Pero aun hay discordancias entre usos del suelo y transportes más llamativas: el acceso al campus de Leioa de la UPV/EHU por transporte público sigue sin obtener una solución satisfactoria, ... ¡ ¡ cuarenta años después de su construcción!. En la actualidad existe un proyecto de construcción de una línea de tranvía específica.

15 Plan aprobado en 2006. (Decreto 179/2006 de 26 de Septiembre. BOPV de 7 de Noviembre de 2006), con un horizonte de 16 años. 
suelo de viviendas para "actividades económicas complementarias". No obstante, a la hora de plantear unas nuevas áreas de actividades económicas, se oferta un total de 242 hectáreas, de las cuales 114 corresponden al Txoriherri, 28 a Getxo y Urduliz, y 100 a Abanto y Ortuella, áreas a desarrollar en un plazo de ocho años a partir de la aprobación de dicho Plan. Muchos de estos destinos laborales solo son alcanzables mediante el transporte privado, y en algunos casos mediante un transporte público deficiente en cuanto a horarios y disponibilidad, y por ello, infrautilizado como ocurre con algunos polígonos de la zona minera ( Campillo en Abanto, Granada en Ortuella).

Se consolida así el Txoriherri como la zona de las nuevas actividades económicas, siendo esta un área de escaso desarrollo residencial, pues supone tan sólo el $1,98 \%$ de la población del A.M.B., el 2,09\% del empleo residente, y el 6,71\% del empleo atraído de la misma, en cifras del censo de 2001. A ello hay que añadir la ausencia de una urbanización residencial compacta, junto con el problema añadido del desarrollo residencial de la zona, muy limitado por los ruidos del aeropuerto sobre las urbanizaciones de baja densidad que se han promovido recientemente. Además hay una carencia de una centralidad simbólica en el área tras una historia urbanística de dependencia de Bilbao: localización del cementerio metropolitano en los años 1940, seminario diocesano, aeropuerto, anexiones de los municipios en los años 1960 a Bilbao, junto con la complejidad administrativa debida a la existencia de múltiples enclaves.

La urbanización relativamente compacta del A.M.B. es un factor que puede ayudar a equilibrar los desequilibrios entre residencia y empleo, buscando la localización de nuevas áreas de actividades económicas también en espacios industriales que perdieron su función, y que tienen una localización relativamente central dentro del conjunto metropolitano.

\section{BIBLIOGRAFÍA}

AGUILERA, A. (2005): Growth in Commuting Distances in French Polycentric Metropolitan Areas: Paris, Lyon and Marseille. Urban Studies, 42:9; 1537-1547.

ARTIGUES et al. (2006) (eds.) Los Procesos urbanos postfordistas. Palma. AGE y Universitat de les Illes Balears.

ALLEN, P.M. y SANGLIER, M. (1979): A dynamic model of growth in a central place system. Geographical Analysis, vol 11,3, 256-272.

AYUNTAMIENTO DE BILBAO (Promotor) (1980): Informe sobre la problemática del Transporte Comarcal en Bilbao. Bilbao.

BLANCO FERNÁNDEZ, J., CARRERO DE ROA, M. (2001): Desplazamientos domicilio-trabajo en el Área Central de Asturias. 1986-1996. Pautas y Causas. III Congreso Internacional de Ordenación del Territorio. Fundicot. Documento electrónico. www.fundicot.org/ciot $\% 203 /$ grupo $\% 202 / 018$.pdf

CALVO PALACIOS, J.L. y PUEYO CAMPOS, A. (1992): "La cartografía de los potenciales poblacionales (1970-1991) como apoyo del análisis económico regional". Papeles de Economía Española, 51, 116-125. 
CASTAÑER, M. et al. (2001): "Las Áreas Urbanas de Cataluña. Las áreas de cohesión", en: Castañer, M., Vicente, J. y Boix, G. (eds): Áreas Urbanas y Movilidad Laboral en España. Girona. Universitat de Girona. 15-35.

CLARK, W.A. V (2000): Monocentric to polycentric: new urban forms and old paradigms en Bridge, G. y Watson, S. (eds): A Companion to the city. Oxford. Blackwell

DAVOUDI, S. (2004). Acerca de la idea de policentrismo en la Estrategia Territorial Europea. En Romero González, J. y Farinós Dasí, J. (eds.) Ordenación del Territorio y Desarrollo Territorial. Gijón. Trea.127-143

DEAR, M. y FLUSTY, S. (1998): Postmodern urbanism. Annals of the Association of American Geographers, 88, 73-80.

DÍEZ NICOLÁS, J. y ALVIRA MARTÍN, F. (dirs.) (1985). Movimientos de Población en Áreas Urbanas Españolas. Madrid. CEOTMA.

ESCOLANO, S. (2006): Cambios recientes en las estructuras espaciales de las grandes ciudades: fragmentación física, segregación socioeconómica y reorganización funcional. En Artigues et al. (eds.) Los Procesos urbanos postfordistas. Palma. AGE y Universitat de les Illes Balears. 103-116.

ESTEBAN, A. DE (1981): Las áreas metropolitanas en España. Un análisis ecológico. Madrid. CIS.

EUSTAT (INSTITUTO VASCO DE ESTADÍSTICA). Censos y padrones de 1986, 1991, 1996 y 2001.

FERIA, J.M. (2004): "Problemas de definición de las áreas metropolitanas en España". Boletín de la AGE 38, 85-99.

FERIA, J.M. (2008): Un ensayo metodológico de definición de las áreas metropolitanas en España a partir de la variable residencia-trabajo". Investigaciones Geográficas, 46,49-68.

FERIA, J.M. (2010): "La movilidad residencial y los procesos de urbanización metropolitanos en España", en Feria Toribio, J.M. y Albertos Puebla, J.M. (coors.): La Ciudad Metropolitana en España: procesos urbanos en los inicios del siglo XXI. Cizur Menor. Thomson Reuters. 23-47.

GOBIERNO VASCO (1994): Directrices de Ordenación Territorial de la Comunidad Autónoma del País Vasco. Servicio Central de Publicaciones del Gobierno Vasco. Vitoria-Gasteiz.

GOBIERNO VASCO (2007): Estudio de la movilidad en la Comunidad Autónoma Vasca. Departamento de Transportes y Obras Públicas. Bilbao.

GRIFFITH, D. A. \& JONES, K.G.(1980): Exploration into the relationships between spatial structure and spatial interaction. Environment and Planning A. 12 (2), 187-201.

GARCÍA PALOMARES, J.C. y GUTIÉRREZ PUEBLA, J. (2007): Pautas de movilidad en el Área Metropolitana de Madrid. Cuadernos de Geografia 81-82. 7-30.

GUTIÉRREZ PUEBLA, J. (1985): El análisis simple de ligazones. Anales de Geografía de la Universidad Complutense. 5, 49-70.

HALL, P.(2000): La redefinición de las ciudades europeas, en Bellet, C. y Llop, J.M. (eds): Ciudades Intermedias. Urbanización y Sostenibilidad. Lleida. Milenio. 391-401.

HALL, P. y PAIN, K. (eds.) (2006): The Polycentric Metropolis. Londres. Earthscan.

HARVEY, D. (1989): The condition of postmodernity: an enquiry into the origins of cultural change. Oxford. Blackwell. (Hay traducción castellana: Buenos Aires. Amorrortu, 1998). 
ISARD, W. (1956): Location and space economy. Cambridge.Massachusetts. MIT Press.

JUARISTI LINACERO, J. (2003): Jerarquía Urbana y Áreas de Movilidad Laboral. Tendencias en el País Vasco en la década de 1990. En López Trigal, L., Relea Fernández, C.E y Somoza Medina, J. (coors.) (2003): La ciudad. Nuevos Procesos. Nuevas Respuestas. León. Universidad de León, 75-84.

LEBER (2008): Reflexión estratégica sobre el sistema de transporte de viajeros en la CAPV y sus clases de actuación. Vitoria. Gobierno Vasco.

MORENO JIMÉNEZ, A. (1980): Jerarquías de núcleos y Áreas funcionales. Análisis con redes de flujos. Estudios Geográficos, 41, 161. 413-446.

MURGA, M. (2010): Costes secundarios y su relevancia para la política de transportes. Ekonomiaz, 73, 102-127.

NAVARRO GÓMEZ, C. (2008): La delimitación y el gobierno del fenómeno metropolitano en España. Anuario de Derecho Municipal. Madrid. Instituto de Derecho Local, 159-184.

NYSTUEN, J.D. \& DACEY, M.F (1961): A Graph Theory of Nodal Regions. Papers of the Regional Science Association, 7: 29-42.

OTEUS (Observatorio del Transporte de Euskadi) (2005): Estudio General de la Sociología del transporte de viajeros en la CAV. Gobierno Vasco. Bilbao.

PLAN TERRITORIAL PARCIAL DEL BILBAO METROPOLITANO (2006). Diputación Foral de Bizkaia. Bilbao.

ROCA CLADERA, J. y MARMOLEJO, C. (2006): Un modelo de interacción espacial aplicado a la distribución metropolitana de la actividad económica. $A C E$. Arquitectura, Ciudad y Entorno, vol 1, n 1, 60-79.

SOJA, E. (2000): Postmetropolis: critical studies of cities and regions. Malden. Blackwell. (Hay version castellana: Madrid, Traficantes de sueños, 2008).

WILSON, A.G. (1970): Entropy in Urban and Regional Modelling. Londres. Pion

\section{APÉNDICE: FÓRMULAS MATEMÁTICAS}

\section{a) Parámetro de fricción de la distancia}

El parámetro de fricción de la distancia $\beta$ desde el origen se ha calculado de acuerdo con una función potencial inversa de la forma $T_{i j}^{\prime}=T_{i *}^{\prime} / d_{i j}^{r}$, siendo $T_{i j}$ el número de viajes con origen en la zona i y destino en la zona j; $T_{i}$ es el número de viajes dentro de la zona o área de origen; y $d_{i j}$ la distancia entre i y j.

En este caso $ß$ se ha obtenido por regresión lineal a partir de la función

$$
\log T_{i j}=\log T_{i^{*}}-\beta \log d_{i j}
$$

\section{b) Índices de Entropía}

Se ha aplicado el índice de entropía de Shannon-Weaver a tres niveles de desagregación de la tabla de movimientos origen/destino: 
- al conjunto de la tabla

- al total de los movimientos de origen (suma de filas)

- al total de los movimientos de destino (suma de columnas)

- a cada lugar (municipio) individual, como índice de diversidad de orígenes (desde los que llega empleo a ese lugar) y como índice de diversidad de los destinos (a los que se dirige el empleo desde ese lugar).

Variables:

Tij son los movimientos que tienen por origen la zona i y por destino la zona $\mathrm{j}$

$O i$ son los movimientos que tienen su origen en $\mathrm{i}$

$D j$ son los movimientos que tienen su destino en $\mathrm{j}$

\section{La entropía total de la Tabla Origen/Destino es}

$H_{i j}=-\sum_{i=1}^{n} \sum_{j=1}^{n} P_{i j} \log _{2} P_{i j}$

Siendo

$P_{i j}=T_{i j} / \sum_{i=1}^{n} \sum_{j=1}^{n} T_{i j}$

de tal forma que $\sum_{i=1}^{n} \sum_{j=1}^{n} P_{i j}=1$

\section{La entropía de los Orígenes es :}

$H_{0}=-\sum_{i=1}^{n} P_{i} \cdot \log _{2} P_{i}$

siendo $P_{i}=O_{i} / \sum_{i=1}^{n} \sum_{j=1}^{n} T_{i j}$

y Oi, la suma de los movimientos con origen en $i$,

es decir $O_{i}=\sum_{i=1}^{n} T_{i j}$

de tal forma que $\sum_{i=1}^{n} P_{i}=1$

\section{La entropía de los Destinos es:}

$$
H_{D}=-\sum_{j=1}^{n} P_{j} \cdot \log _{2} P_{j}
$$


siendo $P_{j}=D_{j} / \sum_{i=1}^{n} \sum_{j=1}^{n} T_{i j}$

y Dj la suma de los movimientos con destino en $\mathrm{j}$,

es decir $D_{j}=\sum_{i=1}^{n} T_{i j(10)}$

de tal forma que $\sum_{i=1}^{n} P_{j}=1$

La entropía para los movimientos con origen en un lugar i, por una parte, y para los destinos en un lugar $\mathrm{j}$, por otra, se definen de forma similar, aplicando el índice de Shannon-Weaver a las probabilidades respectivas, siendo

$$
\begin{aligned}
& P_{(i)}=T_{(i) j} / O_{i} \\
& P_{(j)}=T_{i(j)} / D_{j}
\end{aligned}
$$

\section{La Redundancia para la Tabla Origen/Destino}

$R_{i j}=1-H_{i j} / H_{i j \max }$

siendo $H_{i j \max }=\log _{2} n^{2}$

la redundancia para la distribución de los Orígenes de la Tabla O/D es

$$
R_{o}=1-H_{o} / H_{\text {omax }}
$$

siendo $H_{O \max }=\log _{2} n$

y la redundancia para la distribución de los Destinos en la Tabla O/D es

$$
R_{D}=1-H_{D} / H_{D \text { max }}
$$

siendo $H_{D \max }=\log _{\text {? }} n$

Los valores de la redundancia varían entre 0 y 1 